\title{
Theta phase precession beyond the hippocampus
}

Authors: Sushant Malhotra ${ }^{1,2 \dagger}$, Robert W. A. Cross ${ }^{1 \dagger}$, Matthijs A. A. van der Meer ${ }^{1,3^{*}}$

${ }^{1}$ Department of Biology, University of Waterloo, Ontario, Canada

${ }^{2}$ Systems Design Engineering, University of Waterloo

${ }^{3}$ Centre for Theoretical Neuroscience, University of Waterloo

${ }^{\dagger}$ These authors contributed equally.

*Correspondence should be addressed to MvdM, Department of Biology, University of Waterloo, 200 University Ave W, Waterloo, ON N2L 3G1, Canada. E-mail: mvdm@uwaterloo.ca.

Running title: Phase precession beyond the hippocampus 


\section{Abstract}

The spike timing of spatially tuned cells throughout the rodent hippocampal formation displays a strikingly robust and precise organization. In individual place cells, spikes precess relative to the theta local field potential $(6-10 \mathrm{~Hz})$ as an animal traverses a place field. At the population level, theta cycles shape repeated, compressed place cell sequences that correspond to coherent paths. The theta phase precession phenomenon has not only afforded insights into how multiple processing elements in the hippocampal formation interact; it is also believed to facilitate hippocampal contributions to rapid learning, navigation, and lookahead. However, theta phase precession is not unique to the hippocampus, suggesting that insights derived from the hippocampal phase precession could elucidate processing in other structures. In this review we consider the implications of extrahippocampal phase precession in terms of mechanisms and functional relevance. We focus on phase precession in the ventral striatum, a prominent output structure of the hippocampus in which phase precession systematically appears in the firing of reward-anticipatory "ramp" neurons. We outline how ventral striatal phase precession can advance our understanding of behaviors thought to depend on interactions between the hippocampus and the ventral striatum, such as conditioned place preference and context-dependent reinstatement. More generally, we argue that phase precession can be a useful experimental tool in dissecting the functional connectivity between the hippocampus and its outputs.

Keywords: temporal coding, phase coding, spike timing, ventral striatum, nucleus accumbens, local field potential, decoding, medial prefrontal cortex 


\section{Introduction}

A prominent $\sim 8 \mathrm{~Hz}$ thread runs through the hippocampal literature: pioneering electrophysiological studies in this area revealed a clear "theta" rhythm (Green and Arduini, 1954; Vanderwolf, 1969), which has been at the center of numerous functional and mechanistic theories of hippocampal processing ever since (O'Keefe, 1993; Jensen and Lisman, 1996; Bland and Oddie, 2001; Buzsáki, 2002; Hasselmo, 2005). As a local field potential (LFP) phenomenon, hippocampal theta is susceptible to debate about how such an inherently ambiguous, population-level quantity is to be interpreted ${ }^{1}$. However, the power of the hippocampal theta rhythm as an experimental and theoretical touchstone is clearly illustrated by its relationships to (1) intrinsic membrane properties of individual neurons (Leung and Yim, 1986; Kamondi et al., 1998; Giocomo et al., 2007; Losonczy et al., 2010), (2) spiking and local field potential activity within the hippocampus and anatomically related circuits (Klausberger et al., 2003; Siapas et al., 2005; Colgin et al., 2009; Mizuseki et al., 2009; Battaglia et al., 2011), (3) the efficacy of stimulation protocol timing, relative to theta, in evoking synaptic changes (Larson et al., 1986; Hölscher et al., 1997; Hyman et al., 2003), and (4) hippocampal function and behavior (Sederberg et al., 2003; Manns et al., 2007; Jeewajee et al., 2008). Thus, hippocampal theta links different levels of analysis, accessible with a variety of experimental techniques, across species and brain areas.

A particularly intriguing theta-related phenomenon is theta phase precession, originally observed in hippocampal "place cells"2. O'Keefe and Recce (1993) reported that as a rat traverses a place field, there is a systematic change in the phase of the theta local field potential ${ }^{3}$ at which the cell fires ("firing phase"): the firing phase advances, or precesses, with progress through the place field (Figure 1a-b). Theta phase

\footnotetext{
${ }^{1}$ In general, LFPs reflect summed contributions from synaptic input, membrane potentials, and synchronous spiking, and is further influenced by neuronal morphology and geometrical arrangement of the population. For review, see e.g. Berens et al. (2008).

${ }^{2}$ For brevity, we use "hippocampal" as referring to the hippocampal formation generally, which includes the entorhinal cortex and the subiculum; we will be more specific as required.

${ }^{3}$ The local field potential is typically recorded from the hippocampal fissure, where its amplitude is largest, but the phase precession effect is also apparent relative to the LFP recorded from the cell layer.
} 
precession is a robust and widespread phenomenon, typically observed in dorsal CA1 pyramidal neurons when rodents run along narrow tracks, but also apparent in less restricted environments (Skaggs et al., 1996; Huxter et al., 2008), hippocampal interneurons (Maurer et al., 2006; Ego-Stengel and Wilson, 2007) and other areas in the hippocampal formation (Skaggs et al., 1996; Johnson and Redish, 2007; Hafting et al., 2008; Kjelstrup et al., 2008; Royer et al., 2010).

Two main reasons can be discerned for ongoing interest in theta phase precession. The first is that the precise temporal coordination central to the phase precession effect is a useful tool in dissecting the underlying mechanisms of hippocampal processing. Phase precession inspires and constrains models, particularly when combined with experiments exploring the properties of theta phase precession under various conditions and manipulations (Mehta et al., 2002; Harris et al., 2002; Huxter et al., 2003; Lenck-Santini and Holmes, 2008; Diba and Buzsáki, 2008; Cheng and Frank, 2008; Harvey et al., 2009; Robbe and Buzsáki, 2009). Second, theta phase precession is thought to play a role in mediating hippocampus-specific behaviors or functions, such as spatial navigation, planning or lookahead, and rapid encoding of sequences, including not just spatial trajectories but also episodic-like memories (Skaggs et al., 1996; Jensen and Lisman, 1996; Tsodyks et al., 1996; Yamaguchi, 2003; Shapiro et al., 2006; Leibold et al., 2008; Lisman and Redish, 2009). More generally, theta phase precession stands as one of the clearest examples of a timing (or phase) code in the brain, and is therefore of substantial theoretical interest (Sejnowski and Paulsen, 2006; Nadasdy, 2009; Masquelier et al., 2009; Panzeri et al., 2010).

Given these different ways in which theta phase precession may be important, it is of interest to note that phase precession is also observed in structures outside the hippocampal formation. Jones and Wilson (2005a) found neurons in rat medial prefrontal cortex (mPFC) that phase precess relative to hippocampal theta. Recently, van der Meer and Redish (2011a) reported theta phase precession in the rat ventral striatum (vStr) ${ }^{4}$. Both these structures receive prominent input projections from the hippocampal formation, and are thought

\footnotetext{
${ }^{4}$ We use this general term to refer non-specifically to the area encompassing the nucleus accumbens core, shell, and ventral caudate-putamen in the rat. As with the term "hippocampal" we will be more specific where appropriate.
} 
to mediate the translation of hippocampus-dependent forms of learning and memory into adaptive behavior (Mogenson and Yang, 1991; Mizumori et al., 1999; Poucet et al., 2004; Bast, 2007, 2011). The purpose of this review is to consider how insights about phase precession in the hippocampus can elucidate processing in downstream targets, such as the medial prefrontal cortex and the ventral striatum.

In order to appreciate the potential relevance of theta phase precession for hippocampal output structures, we review current theories on mechanisms and functional relevance of phase precession in the hippocampus itself in the first half of the paper. Readers familiar with these concepts may wish to skip ahead to the second half of the paper (section 4 onwards), which deals with extrahippocampal phase precession. Thus, we start by highlighting the salient experimental data on hippocampal phase precession in the first section (2.1-2.2). In section 2.3 we consider current proposals of how phase precession may be generated. Next, we review the main ideas about the possible functional relevance of hippocampal phase precession (section 3). The following section moves to extrahippocampal phase precession, highlighting the key experimental findings alongside the relevant anatomy (section 4). We then focus on phase precession in the ventral striatum, considering first, possible explanations for how it is generated. We situate the discussion in the context of behaviors thought to involve the hippocampus-ventral striatum pathway, such as conditioned place preference and context-dependent reinstatement (section 5). In the final section, we consider the functional relevance of ventral striatal phase precession, as well as ways to exploit it as an experimental and theoretical tool (section $6)$. 


\section{Theta phase precession in the hippocampal formation}

\subsection{Phase precession in single cells}

The basic theta phase precession effect is readily apparent from observing the spike timing of a single hippocampal place cell relative to the extracellular local field potential (LFP). In the seminal observations of O’Keefe and Recce (1993), as rats traverse a place field along a linear track, place cells spike at progressively earlier phases of the theta LFP. The range over which spike theta phase precesses during a single pass through the field is about $180^{\circ}$ on average, but never exceeds a full cycle (O'Keefe and Recce, 1993; Schmidt et al., 2009). Illustrative single trials and pooled data are shown in Figure 1 and simulated for a pair of adjacent place cells in Figure 4.

[Figure 1 about here.]

At the single cell level, phase precession has a number of implications. Most obviously, it establishes a relationship between location and phase. As the animal first enters a place field, the corresponding place cell tends to fire at late phases of the theta local field potential, but as the animal leaves the place field, the cell has precessed and now fires at early phases. This means that there is information about location in the theta phase of place cell spikes. Indeed, firing phase can correlate better with location than firing rate, particularly when there are variations in running speed (Jensen and Lisman, 2000; Huxter et al., 2003), an idea with potential functional implications we discuss in section 3.

Second, single trial phase precession implies that an individual place cell must spike at a slightly faster frequency than the LFP ${ }^{5}$ A cell that reliably spikes at the same frequency as a particular LFP frequency

\footnotetext{
${ }^{5}$ This is not strictly true: in principle, the cell could spike at a frequency slightly faster than a multiple of the LFP frequency, skipping cycles but still precessing overall. However, this does not seem to happen systematically in biological phase precessing
} 
band is said to be phase locked (or entrained), rather than phase precessing. Phase precession refers to a smooth, gradual phase change over time ${ }^{6}$. The relationship between theta modulation at the single neuron level being slightly faster than the theta LFP frequency is reliable enough that it is often used as a measure or even operational definition of a phase precessing cell (Lenck-Santini and Holmes, 2008; Royer et al., 2010; van der Meer and Redish, 2011a).

A final implication is that the speed of phase precession is related to the size of the place field. Phase precession occurs over a limited range of the theta hhythm $^{7}$, but place fields can have different sizes. This means that for a small place field, this phase range is traversed quickly, whereas for a large place field, phase precesses more slowly. There is a dorsal-to-ventral ${ }^{8}$ gradient in the hippocampus proper (the DG-CA3-CA1 trisynaptic loop) with smaller field, fast phase precessing neurons in the dorsal part, and larger field, slower phase precessing neurons in the ventral part (Jung et al. 1994; Kjelstrup et al. 2008; Royer et al. 2010; see Figure 3). The limited theta range over which phase precession occurs implies that a neuron with fast thetarange interspike intervals (ISIs) will precess rapidly with respect to the LFP. This will cause it to reach the strong-inhibition phase of the theta cycle more rapidly, so it will have a small place field (Geisler et al., 2010). A neuron with a slow ISI (albeit still slightly faster than the period of the LFP) will precess more slowly and have a larger place field ${ }^{9}$.

cells.

${ }^{6}$ There are observations of sudden shifts in theta phase (e.g. Hyman et al. 2011), which when averaged over many trials could in principle create the appearance of a smooth precession effect. However, analysis of single trials shows that theta phase precession is gradual even on single trials (Schmidt et al. 2009; Figure 1).

${ }^{7}$ It is worth noting that in the original O'Keefe and Recce (1993) report, illustrative single trial examples were provided, but for analysis purposes spikes from many passes through the place field were averaged. A recent study (Schmidt et al., 2009) showed that the range of phase precession on single trials is about 180 degrees, significantly less than the range apparent after averaging.

${ }^{8}$ In the primate and human literature, the corresponding terminology is septal-to-temporal.

${ }^{9}$ For simplicity the above assumed a constant speed; a further finesse is that place cells' firing frequency is modulated by speed to ensure that a comparable range of firing phases is covered regardless of speed (Geisler et al., 2007; Burgess et al., 2007; Diba and Buzsáki, 2008). 
Finally, we note that although phase precession at the single cell level has to our knowledge not yet been demonstrated in the human or primate hippocampus, the extant data indicate compelling similarities between human/primate and rodent theta in terms of behavioral correlates and detailed electrophysiological signatures (O'Keefe and Burgess, 1999; Kahana et al., 2001; Ekstrom et al., 2005) suggesting that theta phase precession is of relevance beyond rodent species.

\subsection{A temporal tapestry of theta sequences: phase precession at the population level}

The most surprising and powerful aspects of phase precession are only apparent at the population level. Skaggs et al. (1996) first took the critical step of extending the analysis of hippocampal phase precession to more than one neuron. For two neurons with place fields in close proximity on the track, phase precession imposes a specific fine-timescale structure on the spike timing relationship between the two neurons - beyond what would be expected from the neurons' average firing fields (tuning curves) alone (Dragoi and Buzsáki, 2006; Foster and Wilson, 2007). To see this, consider two place cells A and B, whose fields partially overlap along a track: the subject encounters field A first, followed by field B (Figure 4a, top panel). Imagine first that phase precession is turned off ${ }^{10}$ and place cell spiking is generated stochastically from a spike density function in the shape of the cell's place field. In this case, for a single pass through A and B, cell A will tend to spike before cell B on a behavioral timescale (i.e. how long it actually takes the subject to reach the center of B from the center of A). But on a fine timescale (tens of milliseconds) there will be no discernible relationship between the spike timing from cells A and B (Figure 4a, top panel).

Contrast this with the situation where phase precession is turned on (Figure 4a, bottom panel). The theta phase of cell A's spikes precesses with progress through field A. Therefore, by the time the subject gets to field B, the spikes from A will be more advanced (precessed) than cell B's spikes, which have yet to start their precession. In fact, assuming that cells A and B will precess at similar speeds (as will be the case

\footnotetext{
${ }^{10} \mathrm{~A}$ condition that can be experimentally approximated (Robbe and Buzsáki, 2009), as discussed in section 3.
} 
for similarly sized place fields), this implies that there will be a relatively fixed time interval between cell A and B's spikes. This interval depends on the distance between their place fields: if the fields are very close, then cell B will start precessing only slightly later than cell A, so the time difference will be short. Conversely, if cell A has almost completely precessed before B begins firing, then the time difference will be long (although, of course, not longer than the period of a theta cycle). This effect can be clearly seen experimentally by inspecting the cross-correlograms between place cells with adjacent place fields (Skaggs et al. 1996; Dragoi and Buzsáki 2006; "CCG" plots in Figure 4, top right). Thus, theta phase precession generates a systematic, fine-timescale spike timing relationship between cells with nearby place fields. This observation is particularly notable in the light of experimental observations relating spike timing on this timescale to the direction and efficacy of synaptic plasticity in hippocampal slices (Bi and Poo, 1998); these and other functional implications of phase precession will be discussed in section 3 .

This analysis of phase precession in pairs of place cells extends to populations of place cells, which form sequences of successive locations within a theta cycle (Tsodyks et al., 1996; Jensen and Lisman, 1996; Dragoi and Buzsáki, 2006; Foster and Wilson, 2007; Maurer and McNaughton, 2007; Lisman and Redish, 2009; Gupta et al., 2011; Maurer et al., 2011). Again, imagine a rat traveling along a track covered by place fields $\mathrm{ABCDE}$ from left to right. Within each theta cycle, a sequence of spikes appears, with each cell's spike(s) at a theta phase that reflects the rat's current location relative to that place cell's field. So, if the subject is at location A, cell A's spikes will have phase precessed to some extent, cell B's spikes less so (since it is further away) and cell $\mathrm{C}$ may be just beginning to spike (at a late phase), giving rise to the sequence $\mathrm{ABC}$. As the animal moves to location $\mathrm{B}$, we would see sequence $\mathrm{BCD}$, and so forth. As was the case with the pair of neurons considered previously, the relative distance between place fields translates into a particular spike timing relationship between the corresponding place cells within each theta cycle. Thus, "theta sequences" of place cells appear repeatedly (one per theta cycle) and on a compressed timescale, even though behaviorally, the sequence is only traversed once ${ }^{11}$.

\footnotetext{
${ }^{11}$ For the sake of simplicity this description treated the cells participating in a theta sequence as phase precessing independently. However, there is evidence that the observed level of sequential organization exceeds that of what would be expected from such a scenario (Dragoi and Buzsáki, 2006; Foster and Wilson, 2007) suggesting that network mechanisms play a part.
} 
As memorably put by Bruce McNaughton ${ }^{12}$ this effect is "as a pigeon walks", that is, the represented location (signaled by the currently active place cell) appears to move forward, reset, and move forward again repeatedly (like the pigeon's head) around the subject's true location, which moves more gradually. More precisely, this implies that a decoder which ignores theta phase will decode a location which oscillates at theta frequency around the subject's true location ${ }^{13}$. Thus, while phase precession can be observed at the single cell level, its true power arises from compressed-sequence organization at the population level.

\subsection{Models of phase precession}

[Figure 2 about here.]

There is a complex literature detailing possible contributions to theta phase precession in the hippocampus. In general, these contributions include the passive and active conductance properties of single neurons, local microcircuits, synaptic and network effects, and external inputs. Attempts at integrated models thus face the challenge of accounting for the effects of a wide range of elements, their interactions, and variations between subregions and anatomical aspects of the hippocampal formation. Therefore, our aim in this section is not to compare the state of the art in phase precession models to the data, with the aim of establishing which (combination of) models are the current forerunners; for this we refer the reader to the literature (most recently Burgess and O'Keefe 2011, but see also Maurer and McNaughton 2007; Geisler et al. 2010; Losonczy et al. 2010; Leung 2011; Navratilova et al. 2011). Rather, we will review the types of mechanisms that have been proposed, such that we are in a position to evaluate to what extent these mechanisms may apply to phase precession in areas outside the hippocampal formation.

\footnotetext{
${ }^{12}$ Kavli Institute for Theoretical Physics "Dynamics of Neural Networks: From Biophysics to Behavior" series, UC Santa Barbara 2001, online at http://online.itp.ucsb.edu/online/neuro01/mcnaughton/.

${ }^{13}$ Whether the decoded location is always forward of the subject, rather than symmetric or backward, is a topic of active investigation (Gupta et al., 2011; Maurer et al., 2011).
} 
In discussing possible mechanisms for phase precession, it is important to remember that even within the hippocampal formation, phase precession is found in several subregions. In particular, Hafting et al. (2008) demonstrated that phase precession in the entorhinal cortex persists after inactivation of the hippocampus proper. This suggests that although DG, CA1 and CA3 neurons have access to phase precessing input from the entorhinal cortex (EC), such input is not required for EC neurons to phase precess. Thus, the mechanisms generating it in these regions need not be the same. In line with this view, we will discuss possible mechanisms for phase precession without attempting to map them onto specific subregions. Because the proposals are generally not mutually exclusive, we conceptualize phase precession in any given area as reflecting a particular mixture of different mechanisms. This view is conducive to considering which of these mechanisms may apply to explanations of phase precession beyond the hippocampus (section 4.4).

At the root of explanations for single cell phase precession lies the issue of how it is possible for single cells to oscillate faster than the population LFP. The hippocampal LFP, after all, is shaped by electrical currents ultimately arising from currents generated from those very same cells; more specifically, the LFP is thought to reflect a combination of synaptic currents and membrane potential oscillations (Buzsáki et al., 1983; Leung, 1998; Ylinen et al., 1995; Kamondi et al., 1998). Synaptic contributions to the hippocampal theta LFP likely include inputs from the medial septum, afferent hippocampal subregions such as the entorhinal cortex, and local microcircuits between pyramidal neurons and various interneuron types (Amaral and Lavenex, 2006). Membrane potential oscillations can result from such oscillating inputs, but may be additionally affected by the electrical properties of single neurons. These include passive properties as well as active conductances capable of generating intrinsic oscillations from non-oscillating input, and resonance properties that selectively amplify and suppress particular input frequencies (e.g. Wang 2010). Models of phase precession can be understood as proposals about how these different phenomena interact. We distinguish contributions to phase precession according to the proposed locus where such interaction is placed: (1) within individual phase precessing neurons, which implement some transformation of an input coherent with the LFP; (2) in the organization of a population of neurons assumed to shape the LFP; and (3) in synaptic and network interactions between neurons. 
1. Phase precession arising from within-neuron interactions. Phase precession models of the first type identify the population LFP as corresponding to one of the inputs to a phase precessing cell. The cell then requires one or more additional mechanisms that cause it to oscillate faster than the LFP input which forms the reference for the precession. This class of model has identified several different ways in which operations performed by a neuron may result in phase precession:

- Asymmetric ramping. Mehta et al. (2002) proposed that inhibition at the LFP frequency interacts with an excitatory asymmetric ramping input at the phase precessing neuron. As excitation increases, this will cause excitation to outstrip inhibition (leading to a spike) at progressively earlier phases of the extracellular LFP, resulting in phase precession (Figure 2c).

- Interaction between oscillations of a different frequency. If in addition to an input at LFP frequency, a neuron either receives or generates a second oscillation at a different frequency, an interference or “beat” pattern can result (O’Keefe and Recce, 1993; Bose and Recce, 2001; O'Keefe and Burgess, 2005). In such "dual-oscillator" models, the frequency within each beat will be faster than the LFP, giving rise to phase precession (Figure 2a). A variation of this model occurs when one of the oscillations is frequency-modulated; in this case, two oscillations can be out of phase outside the neuron's place field, but in phase in the place field (Figure 2b). As long as both oscillations are faster than the LFP, the resulting spikes will phase precess (Lengyel et al., 2003; Yamaguchi et al., 2007).

- Interaction between oscillations of the same frequency. If two inputs to a neuron have the same frequency but differing phase, then a shift in the balance between these inputs can cause phase changes in a neuron that integrates these inputs (Kamondi et al. 1998; Leung 2011, Figure 2f). A number of factors may contribute to an on-line modulation in this balance as to result in phase precession, such as externally imposed changes in the amplitudes of the input (Magee, 2001), synaptic adaptation (Thurley et al., 2008), or changes in the driving force of excitatory and inhibitory inputs due to depolarization (Kamondi et al., 1998; Leung, 2011). This type of interaction is sometimes referred 
to as "somato-dendritic interference" (SDI), in reference to the likely origin of the two component oscillations. However, it is not to be confused with "dual-oscillator" models in which two different frequencies interact to produce a true interference or "beat" pattern.

- Active properties. Particular types and distributions of voltage-gated channel properties can endow a neuron with the ability to generate membrane potential oscillations in response to non-oscillating input, and/or to selectively amplify and phase shift particular input frequencies (Leung and Yu 1998; $\mathrm{Hu}$ et al. 2009, Figure 2e). These properties may modulate oscillations that participate in the above models, thereby contributing to phase precession (Leung, 2011).

2. Phase precession arising from the neuron-to-LFP transformation. A different view does not focus on the ways in which a single neuron comes to phase precess given a LFP input, but instead asks how the population LFP can result from particular arrangements of individually precessing neurons. Geisler et al. (2010) showed that the membrane potential oscillations (MPOs) of a population of place cells can sum to a simulated LFP of a slower frequency than any of the individual cells (Figure 2d). This surprising possibility relies on a specific pattern of offsets (temporal delays) between the MPOs of individual place cells, for which there is experimental evidence (Geisler et al., 2010). Thus, this view highlights the fact that since the phase precession effect is about a relationship between spikes and the LFP, contributions to it can occur not just in the transformation from LFP to spikes (as in single neuron models) but also in the transformation from spikes to LFP.

3. Phase precession arising from network effects. Network-level explanations for theta phase precession do not require single neurons to have specific oscillatory properties, but instead rely on synaptically mediated interactions between neurons. A prominent such class of model is based on the so-called attractor network, which conceptualizes hippocampal activity as an "activity packet" that moves around on a two-dimensional surface of place cells (Samsonovich and McNaughton, 1997). This activity pattern represents the rat's current location, tracking it as the rat moves location as it moves based on sensory input from as visual, vestibular, 
and other systems. Critically, the network is not tied to these inputs, but has internal dynamics that allow it to move by itself. For instance, recurrent connections in CA3 are thought to allow the spread of activity in the absence of external input. If these synaptic connections are structured to be asymmetric (i.e. favour a spread of activity corresponding to a forward direction), phase precession can result (Tsodyks et al., 1996; Jensen and Lisman, 1996; Wallenstein and Hasselmo, 1997). This occurs because for place fields corresponding to the rat's current location, sensory input is largest leading to an early firing phase. Place fields ahead of the animal are less activated by sensory input but more by spreading activation, but because this is delayed by transmission through a chain of place cells, these will fire at a later phase. There is striking evidence that the required asymmetry can develop with experience, at least on one-dimensional tracks (Mehta et al., 1997).

Thus, in summary, a number of mechanisms have been proposed as contributing to phase precession. Following previous reviews (Maurer and McNaughton, 2007; Burgess and O'Keefe, 2011) we distinguish cellintrinsic and network mechanisms, as well as the mapping from cells to LFP. These mechanisms are not mutually exclusive, and much ongoing experimental and theoretical work attempts to resolve the ways in which they interact (e.g. Navratilova et al. 2011). Here, discussion of these potential mechanisms forms a basis for exploring which of these apply to understanding phase precession beyond the hippocampus.

\section{Functional relevance of phase precession}

The possible mechanistic sources discussed in the previous section are agnostic about whether phase precession is useful or not. However, several authors have noted that phase precession may be functionally important for some of the known contributions of the hippocampus to behavior. These ideas, reviewed in this section, are typically embedded in "learning and memory" views of hippocampal function, including spatial navigation and episodic(-like) memory (Redish, 1999; Morris, 2006), rather than in affective processing and sensorimotor views (Gray and McNaughton, 2000; Bland and Oddie, 2001; Bast and Feldon, 2003; Bannerman et al., 2004). These different views of hippocampal function map onto anatomical dissociations 
between hippocampal aspects, with learning and memory functions primarily associated with the dorsal hippocampus and affective/sensorimotor processing primarily with the ventral aspect (Moser and Moser 1998; Bast 2007; Fanselow and Dong 2010; see Figure 3). The focus on learning and memory in functional ideas about phase precession may be justified given the parallel gradient observed in the distribution of theta phase precession, which is more prevalent in the dorsal hippocampus compared to the ventral hippocampus (Royer et al., 2010). However, phase precession is by no means absent from the ventral hippocampus (Kjelstrup et al., 2008; Royer et al., 2010), leaving open the possibility that phase precession may play a role in affective processing as well.

[Figure 3 about here.]

\subsection{Phase coding}

We distinguish three main ideas about how theta phase precession might support what the hippocampus does. The first - phase coding - builds directly on the observation that on the single cell level, theta phase is related to the animal's location within a place field (O'Keefe and Recce, 1993). This implies that a decoder receiving hippocampal place cell input could potentially exploit this phase information. In support of this idea, Jensen and Lisman (2000) showed, on the basis of actual recording data, that a decoder that takes the theta phase of each spike into account can obtain a more accurate read-out of the location of the animal, compared to a decoder that ignores phase. Thus, in the context of the role of the hippocampus in tasks that require a representation of the animal's current location (such as homing, shortcut, and allocentric goal finding) the accuracy boost provided by a phase-sensitive decoder could improve performance on navigation tasks.

A requirement for a downstream area to be able to read out the phase code is that it needs to have access to LFP phase (Jensen, 2001; Nadasdy, 2009). An extracellular theta rhythm coherent with hippocampal theta is present in both medial prefrontal cortex (Benchenane et al., 2010) and ventral striatum (Berke et al., 2004), 
but it is not currently known if areas that receive input from the hippocampus in fact use phase information in this way. However, the idea of phase coding is not limited to improved spatial representation. Experimental demonstrations that rate and phase can be dissociated to a certain degree (Hirase et al., 1999; Huxter et al., 2003) raise the possibility that distinct messages may be coded by rate and phase respectively (O'Keefe and Burgess, 2005). For instance, in 2D environments, phase information can be used to extract the animal's direction of travel (Huxter et al., 2008), and on nonspatial tasks, phase can distinguish between the encoding and recall of experience (Manns et al., 2007). Likewise, a number of rate correlates have been identified, including running speed (McNaughton et al. 1983, but see Geisler et al. 2007), features of the environment (O'Keefe and Speakman, 1987; Leutgeb et al., 2005b), and sequential context (Eichenbaum et al., 1999).

[Figure 4 about here.]

\subsection{Rapid storage of sequential experience}

The second idea about the functional relevance of hippocampal phase precession is that it enables the rapid storage of experience. As discussed in the previous section, when viewed at the population level, theta phase precession implies that each theta cycle contains a coherent, compressed sequence of nearby place cells (Dragoi and Buzsáki, 2006; Foster and Wilson, 2007; Gupta et al., 2010; Maurer et al., 2011). As originally noted by Skaggs and McNaughton (1996) this results in a cross-correlogram peak that depends on the distance between the place fields. This observation is potentially critical given results on spiketiming dependent plasticity in the hippocampus. These experiments show that the change in synaptic efficacy between neurons A and B depends on their relative spike timing, such that if A reliably spikes before B, their

connection strength is increased, and if conversely B spikes before A, their connection strength is decreased (Hebb, 1949). Crucially, the time window for such changes to occur appears to be limited to about 40 ms at most, at least in slice preparations (Bi and Poo, 1998). As illustrated in Figure 4, without phase precession there would not be much asymmetry in this $40 \mathrm{~ms}$ time range in the cross-correlogram between 
two sequentially arranged place cells, and thus the resulting increase in synaptic efficacy would be weak. In contrast, with phase precession, the precise temporal coordination between subsequently arranged place cells creates a large cross-correlogram asymmetry in the spike-timing dependent plasticity (STDP) range. Thus, the resulting increase in synaptic strength is much larger. Several authors have noted that this combination of temporal coordination within a theta cycle and repeated sequential ordering across theta cycles is well suited to the rapid storage of experience (Yamaguchi, 2003; Buzsáki, 2005; Leibold et al., 2008). Given the well-documented role of the hippocampus in rapid learning in rodents and episodic memory in humans (O'Keefe and L, 1978; Redish, 1999; Morris, 2006), this is a salient point.

The rapid storage view of hippocampal phase precession predicts a relationship between the fidelity or temporal precision of phase precession and subsequent memory. In support of this idea, there is a body of results showing that theta oscillations more generally are related to successful encoding (Sederberg et al., 2003; Shirvalkar et al., 2010; Rutishauser et al., 2010; Addante et al., 2011). To our knowledge, the only study to date to address the relationship between phase precession and memory-dependent performance specifically is Robbe and Buzsáki (2009). In this important study, the authors used a cannabinoid to disrupt hippocampal phase precession while leaving place fields stable and intact. Using a hippocampal-dependent delayed alternation task, it was found that the loss of phase precession was correlated with the magnitude of the performance impairment. A possible explanation in line with a role for phase precession in rapid encoding would be that without phase precession, the rats were not able to store the preceding trial for maintenance across the delay. Although other explanations may be consistent with the data also (e.g. phase precession may be important for the active maintenance of a previous-trial-dependent state through the delay period, or the rat's ability to recall the previous trial may be impaired, or the hippocampus's ability to synchronize with downstream structures may be affected) this is the first study to link disruption of phase-precession to a behavioral deficit.

Despite these suggestive results, it is not immediately clear that the rapid storage of place cell sequences equates to a component of episodic memory. To help bridge this gap, it has been noted that hippocampal 
neurons have nonspatial (or perhaps more accurately, supra-spatial) correlates as well, in line with O'Keefe and Nadel (1978)'s original conception of the cognitive map (Leutgeb et al., 2005b; Manns et al., 2007). In humans, hippocampal neurons can have remarkably specific tuning, being activated by the viewing and recall of, for instance, particular features of TV show clips (Gelbard-Sagiv et al., 2008). Thus, it is conceivable that the episodic encoding of attended experience - which may not be exclusively spatial - leads to sequential activation of hippocampal neurons, potentially subject to the same phase precession rapid storage benefits as sequences of place cells. Studies examining the structure of nonspatial (Fortin et al., 2002; Ginther et al., 2011) or internally generated (Pastalkova et al., 2008) sequences in the rodent hippocampus, alongside highresolution imaging and intracranial recording studies in humans (Jacobs et al., 2007; Doeller et al., 2010) have started to bridge this gap.

\subsection{Lookahead}

The final idea about functional relevance of theta phase precession - lookahead - is that it implements a forward-looking mechanism that may be useful for decision-making that relies on the explicit representation of upcoming places or outcomes, i.e. planning ${ }^{14}$. Again, this view is in principle agnostic about how this phenomenon is generated. It merely points out that a downstream structure receiving hippocampal inputs (a decoder) could extract position information that periodically (at theta frequency) sweeps ahead of the animal. As discussed in section 2.2, when viewed at the population level, phase precession implies that within each theta sequence, a coherent sequence of place cells is activated. Thus, a simple decoder that does not use theta phase to improve its location estimate but is only sensitive to the identity of the spikes (representing location as the peak of each neuron's place field, for instance) would have access to past locations early in the theta cycle and upcoming locations late in the theta cycle (Jensen and Lisman, 1996; Jensen, 2001). As outlined by Lisman and colleagues, when the animal is at a location corresponding to the center of place cell $\mathrm{C}$, a

\footnotetext{
${ }^{14}$ Thus, we distinguish lookahead as only one component of an integrated planning process. Planning requires not just the generation of potential outcomes (lookahead) but also their evaluation, and translation to action (van der Meer and Redish, 2010).
} 
given theta cycle typically contains the sequence ABCDE, that is, starting some way behind the animal's current location and ending ahead of it.

The ability to represent upcoming locations is potentially useful for a number of behaviors that are known to require the hippocampus. A classic example is the ability to choose a path to an allocentrically defined goal from different starting locations (“locale navigation" in O'Keefe and L 1978), as occurs in certain Morris water maze protocols (Morris et al., 1982; Sutherland et al., 1987; Pearce et al., 1998) and plus maze probe trials (Tolman et al., 1946b). A related ability is the planning of shortcuts (Tolman et al., 1946a; Alvernhe et al., 2008), although phase precession has not yet been systematically studied in the context of not-yet experienced paths, which occur in the hippocampus during (p)replay events (Gupta et al., 2010; Dragoi and Tonegawa, 2010). As with the rapid sequence storage view, above, the lookahead view is in principle not limited to spatial lookahead alone. To the extent that hippocampal neurons can represent non-spatial variables or outcomes, these could participate in lookahead also. In support of this idea, there is evidence from instrumental conditioning (lever-pressing) tasks that the hippocampal formation is involved in representing outcome information required for sensitivity to devaluation of the outcome (Corbit et al., 2002), and that anticipatory representations in prefrontal areas depend on the hippocampus (Ramus et al., 2007; Burton et al., 2009). Thus, the known involvement of the hippocampus on tasks that require representations of upcoming paths or outcomes is congruent with the idea that phase precession enables such forward-looking representations.

An obvious limitation of this interpretation is that lookahead deriving from phase precession has a finite range: on spatial tasks, typically not more than about $50 \mathrm{~cm}$ ahead of the animal in dorsal CA1 cells (Foster and Wilson, 2007; Maurer et al., 2011; Gupta et al., 2011); it is presently unclear if the extended lookahead events observed during theta in dorsal CA3 by Johnson and Redish (2007) are a special case of phase precession. In any case, a well established result in the reinforcement learning literature is that even limited lookahead is potentially useful, given access to a state value function that estimates the value of states that are not themselves rewarded (Dyna-Q: Sutton 1990; Sutton and Barto 1998). On T-mazes, a value function 
such as one learned by typical temporal-difference reinforcement learning (TDRL), would back-propagate from the reward sites ${ }^{15}$. Thus, for different reward values at either side of the maze, a limited lookahead would encounter a difference in values if they are sufficiently backpropagated by the TDRL algorithm. Furthermore, to the extent that ventral hippocampal neurons with their larger place fields form coherent theta sequences, the range of lookahead would be correspondingly extended.

Although there is currently little experimental evidence for this particular possible function of phase precession, the possibility of selectively disrupting phase precession (Robbe and Buzsáki, 2009) opens up approaches that could address this issue. For instance, a detailed analysis of behavior including pausing at the choice point (Blumenthal et al., 2011) or comparison of different RL model variants to trial-by-trial choice (Samejima et al., 2005; O’Doherty et al., 2007; Huh et al., 2009; Ito and Doya, 2011) could potentially narrow down the precise nature of the behavioral impairment in the Robbe and Buzsáki (2009) study.

\section{Phase precession outside the hippocampus}

Given the insights theta phase precession has afforded into the mechanics of hippocampal processing, and its potential for functional relevance, it is of interest that theta phase precession extends to at least two of the hippocampus's major afferents: the medial prefrontal cortex (mPFC) and the ventral striatum (vStr). It is worth noting from the outset that, since there are currently only two published experimental reports on extrahippocampal theta phase precession, many open questions are not yet explored, and even speculations based on those results will be preliminary because of the limited data. However, since both HC-mPFC and HC-vStr interactions are the subject of a rich literature, which has recently benefited from simultaneous

\footnotetext{
${ }^{15}$ Briefly, TDRL is a reinforcement learning algorithm that learns which actions to take, based on how well these actions turned out in the past. In order to learn about actions that are not themselves rewarded, but contribute to receiving reward later, it computes the values of intermediate (non-rewarded) states: the TDRL value function. For review, see Sutton and Barto (1998); van der Meer and Redish (2010)
} 
multi-structure recording studies, even these initial reports on phase precession can be situated in a useful context. With this in mind, we turn first to the main experimental findings on extrahippocampal phase precession.

\subsection{Theta phase precession in medial prefrontal cortex}

Jones and Wilson (2005a) were the first to report theta phase precession outside the hippocampus. Using a modified T-maze, they found that as animals approached the decision point, theta band coherence between $\mathrm{HC}$ and $\mathrm{mPFC}$ local field potentials increased. Along with this increased coherence, theta phase precession was apparent in mPFC, both in single neuron examples and after averaging all recorded neurons within subjects ${ }^{16}$. It was also possible for phase precession to occur at other points in the track, but the effect was clearest as animals approached the decision point. This decision-point specific pattern is congruent with an emerging literature that theta-band coordination between $\mathrm{HC}$ and $\mathrm{mPFC}$ is important in the selection of appropriate location-specific actions or strategies (Floresco et al., 1997; Benchenane et al., 2010; Hyman et al., 2010; Sigurdsson et al., 2010; Womelsdorf et al., 2010), which would be preferentially manifest at decision points. Thus, given the prominent HC projection to the mPFC (Swanson, 1981; Jay and Witter, 1991; Thierry et al., 2000), a reasonable first explanation for how mPFC phase precession arises is to propose that it simply reflects increased hippocampal drive of mPFC neurons, which inherit the phase characteristics of the hippocampal afferents driving them. This "baseline" account of extrahippocampal phase precession will be a recurring theme, and it suggests that a comparison of hippocampal phase precession with that in extrahippocampal structures is informative in evaluating this explanation.

\footnotetext{
${ }^{16}$ Note that in this study, as well as in the ventral striatal phase precession discussed in the next section, phase precession was typically considered relative to the hippocampal theta rhythm. Theta can be recorded locally from mPFC and vStr, but is typically smaller in amplitude than theta recorded from the hippocampal fissure, such that phase precession is clearer when the HC LFP is used. However, in line with the theta coherence observed between $\mathrm{HC}$ and the extrahippocampal phase precessing structures, van der Meer and Redish (2011a) showed that ventral striatal phase precession is also apparent relative to the ventral striatal theta rhythm.
} 
For instance, as reviewed in the section on single cell properties of theta phase precession, HC phase precession occurs over a limited range of the theta cycle, especially on a trial by trial basis (Figure 1). HC neurons also phase precess with a characteristic speed, which is inversely related to the size of their place field and which decreases along the dorsal to ventral axis. However, Jones and Wilson (2005a) noted that even in individual mPFC neurons, it was possible to observe phase precession that extended over more than a theta cycle (360 degrees). Given the single-trial observations of Schmidt et al. (2009) an analysis of whether this large phase range in mPFC occurs on single trials, or arises because of averaging instead, would be of interest. In principle, however, this extended range would suggest that phase precessing mPFC neurons do not simply transmit "copies" of a particular hippocampal firing pattern. Likewise, the phase precessing mPFC cells in Jones and Wilson (2005a) precessed at a speed comparable to simultaneously recorded dorsal CA1 neurons. This would suggest the possibility that dorsal CA1 neurons contribute to mPFC phase precession. However, in order to create the observed phase range and spatial distribution of phase precession in mPFC, it would not be sufficient to simply replicate CA1 firing patterns, which are more uniformly distributed over the track, rather than focused around the decision point, and have a narrower theta range over which they precess. Although further studies beyond this initial report would be valuable, comparisons such as these illustrate how phase precession in neurons beyond the hippocampus could be used as a tool to infer possible inputs to such neurons; we will return to this point in section 6.

\subsection{Theta phase precession in the ventral striatum}

Recording from the ventral striatum as rats ran a spatial decision task, van der Meer and Redish (2011a) found clear theta phase precession in individual neurons as well as in the population. Strikingly, neurons with a characteristic "anticipatory ramping" firing pattern up to the reward sites (commonly reported in the ventral striatum across different tasks and species; Schultz et al. 1992; Lavoie and Mizumori 1994; Carelli and Deadwyler 1994; Miyazaki et al. 1998; Tremblay et al. 1998; Hollerman et al. 1998a; Hassani et al. 2001; Daw 2003; Cromwell and Schultz 2003; Khamassi et al. 2008), tended to show the strongest phase 
precession. There were also a few neurons which phase precessed up to the decision point, reminiscent of the mPFC phase precession in Jones and Wilson (2005a). However, a population-level comparison with simultaneously recorded dorsal CA1 neurons revealed a contrast where the CA1 population showed precession throughout the task, but the ventral striatal population only precessed up to the decision point and the reward sites (see Figure 1 for illustrative examples). Thus, ventral striatal phase precession was restricted to a subset of neurons, and this population exhibited task-related firing patterns, apparently associated with the decision point and reward sites - unlike phase precession in dorsal CA1.

By analogy to the mPFC case, it is of interest to determine in what ways vStr phase precession is similar or different to that in the hippocampus. van der Meer and Redish (2011a) noted that the phase range over which vStr cells precessed was similar to that of hippocampal cells (close to $360^{\circ}$ when averaged over multiple passes); however, this range was $180^{\circ}$ out of phase with the simultaneously recorded dorsal CA1 population. Royer et al. (2010) recorded phase precessing cells in ventral hippocampus (CA3) and found that the phase range of these cells was similarly $180^{\circ}$ out of phase relative to dorsal hippocampal phase precession. Taken together, these results suggest that in accordance with the predominantly ventral hippocampal origin of the HC-vStr projection (for recent reviews, see Haber 2009; Sesack and Grace 2010; Humphries and Prescott 2010), and the approximately 180 degree phase shift in dorsal and ventral theta (Lubenov and Siapas, 2009) theta phase precession in the ventral hippocampus and the ventral striatum occurs over a similar range. As in the $\mathrm{mPFC}$ case, this similarity likely reflects the contribution of phase precessing hippocampal input to ventral striatum.

A further notable property of the phase precessing ramp cells in van der Meer and Redish (2011a) arose because of the structure of the task, which had multiple reward sites. The majority of ramp cells showed a larger (higher firing rate) ramp up to the first reward site, and a smaller (lower firing rate) ramp up to the second reward site, even though the rewards delivered at these sites were similar (two $45 \mathrm{mg}$ food pellets). Yet, in both ramps, phase precession occurred over a similar range of the theta cycle. Thus, theta phase was dissociable from firing rate, raising the possibility that temporal and rate codes in ventral striatum can 
carry independent messages. In the context of hippocampal place cells, Huxter et al. (2003) proposed that theta phase could code for position (progress through the place field) leaving firing rate free to code for other variables such as running speed or more 'episodic-like' properties such as the presence or absence of particular objects or other features of the environment (O'Keefe and Speakman, 1987; Leutgeb et al., 2005b). Although at this time we can only speculate, the observed rate/phase dissociation in ventral striatal ramp cells is consistent with a similar dual coding scheme: for instance, theta phase could indicate distance from a reward site, with firing rate indicating the expected value of the reward. This idea could be tested by recording the activity of phase precessing ramp neurons in a task that systematically varies distance to reward and reward value.

Thus, although the properties of single cell theta phase precession in mPFC and vStr have similarities with that in hippocampal cells, at the population level there are clear differences. In particular, extrahippocampal phase precession does not appear to be uniformly distributed over space on T-maze tasks, but rather specifically associated with decision points and reward sites. Hence, to the extent that hippocampal inputs to mPFC and vStr shape theta phase precession, some degree of selection or modulation of that input has to take place. We expand on this "selective inheritance" interpretation in section 4.4.

\subsection{Anticipatory ramp cells in the ventral striatum}

The strong association of ventral striatal phase precession with a particular "anticipatory ramp" firing pattern suggests that its mechanisms and functional relevance are somehow intertwined with the properties of these cells. What could these ventral striatal ramp cells be coding for? The intuitive interpretation that they reflect anticipation of aspects of reward has generally been upheld by the data, although many open questions remain. A series of studies by Schultz and colleagues using reaching tasks in monkeys revealed a variety of reward-related signals throughout the striatum, including ramp-like activity up to reward delivery in ventral striatum (Apicella et al. 1991; Schultz et al. 1992; Hollerman et al. 1998b; Tremblay et al. 1998; Hassani 
et al. 2001; Cromwell and Schultz 2003; Cromwell et al. 2005; see Tremblay et al. 2009 for a recent review). Of course, these tasks are very different from the rodent T-maze where ventral striatal phase precession was originally found; thus, even quite apart from biological primate/rodent differences, the activity of ventral striatal cells in primate reaching tasks may not be comparable to those in van der Meer and Redish (2011a). However, there are striking similarities between the ramping signals observed in primate and rodent ventral striatum (Carelli and Deadwyler, 1994; Miyazaki et al., 1998; Carelli et al., 2000; Daw, 2003; Mulder et al., 2005; Khamassi et al., 2008; van der Meer and Redish, 2009). In particular, the properties of ventral striatal ramp cells can be summarized with a few key properties: (1) ramp cell activity can distinguish between the predicted amount, and (2) the identity of reward outcomes; (3) this activity cannot be explained by potential covariates such as chewing or other anticipatory movements, and (4) there appears to be a distributed code for reward value, with some neurons ramping more (higher activity) as rewards get smaller. There are also examples of ramping up to instruction and trigger cues, which are not themselves rewarded but may function as conditioned reinforcers.

How might anticipatory ramp cells in ventral striatum contribute to behavior ${ }^{17}$ ? Not unlike current theories of ventral striatal function more generally, distinct contributions to learning and ongoing behavior can be discerned (van der Meer and Redish, 2011b). In particular, it has been suggested that ramping activity in ventral striatum reflects a state value signal as would be expected from temporal-difference reinforcement learning (TDRL) algorithms (Daw, 2003; Khamassi et al., 2008; van der Meer and Redish, 2011a). By assigning values to intermediate states (such as conditioned reinforcers) which are not themselves rewarded, agents can learn relationships between actions which are temporally distant from resulting outcomes (i.e. solve the credit assignment problem). Placing this state value signal in vStr is consistent with a body of anatomical, lesion, and fMRI evidence (see van der Meer and Redish 2011b; Ito and Doya 2011; Bornstein and Daw 2011 for recent reviews), and the known role of vStr modulating dopamine neuron activity in

\footnotetext{
${ }^{17}$ We note that anticipatory ramp-like signals have been observed in multiple other brain areas, often with anatomical links to the ventral striatum, such as the dorsomedial prefrontal cortex, dorsal raphe, the ventral tegmental area, and even the ventral hippocampus. The issue of how the contributions of these areas within an interconnected network might be disentangled is beyond the scope of this review; for ideas, see e.g. Hare et al. (2008); Roesch et al. (2010); Salzman and Fusi (2010).
} 
response to rewards (Tremblay et al., 2009; Sesack and Grace, 2010). The activity of ramp cells maps well onto the expected firing pattern of state value functions, including the higher firing rate up to the first reward compared to the second in van der Meer and Redish (2011a). However, when Khamassi et al. (2008) explicitly compared predictions of TDRL to ramp cell firing, they found significant deviations. For instance, when animals were scheduled to receive a number of rewards in sequence, anticipatory firing differed widely between identical rewards. A possible explanation advanced by Khamassi et al. (2008) was variability in the input state to the model algorithm, that is, the rats were uncertain about how many rewards they could expect. Other possibilities could include the idea that value in ramp cells is encoded in a distributed manner not just across values and outcomes, as reviewed in the preceding section, but also across states: in this scenario, a given ramp cell would contribute to value coding only in a subset of states. Another idea is that the ramp cell signal does not exclusively reflect past, cached values as in TDRL, but also contains a contribution from current motivational (incentive) processes. Such a function is in line with the known role of ventral striatum in invigorating or energizing ongoing behavior, either generally or directed towards specific cues or outcomes (Ikemoto and Panksepp, 1999; Cardinal et al., 2002; Wise, 2006; Nicola, 2007; Salamone et al., 2007; Berridge, 2007); the fact that anticipatory ramping appears to be observed toward specific outcomes, as well as more generally, suggests that ramp cells may instantiate a component of this vStr function. Although there have been few reports linking the activity of ramp cells specifically with behavior (but see Tremblay et al. 1998), in human fMRI studies there is now a substantial body of work implicating reduced vStr reward anticipation in neurological disorders such as ADHD and addiction (Scheres et al., 2007; Beck et al., 2009; Peters et al., 2011).

Thus, a speculative function is emerging for ramp cells in supporting learning and performance functions in motivated behavior. In section 6, we develop the idea that theta phase precession in these cells can not only be a useful tool in exploring this idea, but may also be functionally important. To set the stage, we first turn to the possible mechanisms for ventral striatal phase precession. 


\subsection{Possible mechanisms for ventral striatal theta phase precession}

As reviewed in section 2.3, a number of mechanisms have been proposed for the de novo generation of theta phase precession in the hippocampus. Recall that these include (1) modification of LFP-frequency input(s) by single neurons into a faster oscillation, (2) a population of oscillating neurons summing to a slower LFP, and (3) spread of activity through network mechanisms. In addition, for extrahippocampal phase precession, there is potential for (4) selective inheritance of hippocampal phase precession patterns. We consider these possibilities in turn.

Single-neuron contributions. Intracellular recordings from medium spiny neurons (MSNs, the striatal projection neuron making up $\sim 90 \%$ of neurons) have reported theta oscillations in the membrane potential (O’Donnell and Grace, 1993; Leung and Yim, 1993) that persisted even after inactivation of hippocampal input (O’Donnell and Grace, 1995). However, the magnitude of low threshold spikes and afterhyperpolarizations in MSNs (possible mechanisms for the intrinsic generation or sustaining of membrane oscillations; O’Donnell and Grace 1993) were found to be (1) insufficient to sustain intrinsic oscillatory activity, and (2) absent from those cells that showed theta oscillations. Thus, O'Donnell and Grace (1995) concluded there is little evidence for intrinsic generation of theta activity in MSNs. Similarly, intracellular recordings from striatal fast-spiking interneurons (FSIs) revealed no evidence for intrinsic membrane properties conducive to theta generation, although clear gamma oscillations were found upon depolarization (Taverna et al., 2007). Thus, so far, there seems to be little positive evidence for the intrinsic generation of theta oscillations in ventral striatal neurons as required by some phase precession models.

In the absence of internally generated theta oscillations, single vStr neurons could contribute to phase precession by operating on theta-modulated inputs. Theta components are present in the ventral striatal LFP (likely reflecting contributions from hippocampal and prefrontal inputs, although the decisive experiments have not been done), as well as in MSN and FSI spiking (Berke et al., 2004; Lansink et al., 2009; Gruber et al., 2009; Berke, 2009; van der Meer and Redish, 2011a). This means that in principle, asymmetric ramping 
and somato-dendritic interference (SDI) could contribute to ventral striatal phase precesssion. However, the asymmetric ramping model predicts a tight rate-phase relationship, incompatible with the clear dissociation in the data (van der Meer and Redish, 2011a). To our knowledge the possibility of SDI in striatal MSNs, deriving from the conjunction of perisomatic FSI-MSN inhibition (Tepper et al., 2008) and dendritic excitation with different theta phases, has not yet been examined. Given the extensive differences in the physiology and morphology of neuronal, synaptic and network organization between the hippocampus and the striatum, it seems unlikely that large, local contributions to theta phase precession exist in the ventral striatum.

Population contributions to the LFP. The idea that fast-oscillating phase precessing neurons can organize such that a slower LFP results, could apply to vStr. It is currently unknown if vStr phase precessing cells display the required organization, but in any case, this contribution does not address how rhythmic spiking itself is generated.

Network effects. Striatal MSNs send relatively sparse GABAergic collaterals to other MSNs, as well as to FSIs, which in turn broadly and powerfully inhibit nearby MSNs (Taverna et al., 2007; Tepper et al., 2008; Berke, 2011). Network explanations of phase precession rely on a coherent ensemble representation (e.g. of space, as in the hippocampus) with internal dynamics. Studies of ventral striatal ensemble recordings revealed little support for a coherent representation of space (van der Meer et al., 2010a) although this does not exclude the existence of a representation for other, motivationally related variables. The degree to which ventral striatal representations exhibit internal dynamics is an issue of interest for future work.

Selective inheritance. Thus, noting that certain ventral striatal contributions to "locally generated" phase precession appear possible in principle, there is currently little evidence that this in fact occurs. Given that vStr receives prominent input from the hippocampus, of which at least some proportion of cells likely already displays phase precession, the most straightforward explanation of ventral striatal phase precession appears to be "selective inheritance". In fact, as a site of convergence, the ventral stratum receives projections from multiple areas known to exhibit theta oscillations, including the hippocampus (Buzsáki, 2002), 
prefrontal cortical areas (Jones and Wilson, 2005b; van Wingerden et al., 2010), the amygdala (Paré, 2002; Seidenbecher et al., 2003), the ventral tegmental area (Kocsis et al., 2001) and the dorsal raphe (Kocsis and Vertes, 1992). It is also notable that the medial septum, a structure known to provide an important theta input to the hippocampus (Petsche et al., 1962; Koenig et al., 2011; Brandon et al., 2011) is physically adjacent to the ventral striatum, and thus volume conduction from this area could contribute to ventral striatal theta. Although it is possible that theta-modulated inputs from all these sources contribute to ventral striatal theta, there are several indications that the hippocampal input in particular, is a major contributor. In line with the prominent projections from multiple hippocampal subfields (CA1, subiculum, and entorhinal cortex; Groenewegen et al. 1987; Brog et al. 1993; Finch 1996; Groenewegen et al. 1999; Voorn et al. 2004; Haber 2009; Sesack and Grace 2010; Humphries and Prescott 2010), theta LFP oscillations and spiking activity in the ventral striatum cohere with simultaneously recorded hippocampal activity in a task-related manner (Martin and Ono, 2000; Martin, 2001; Tabuchi et al., 2000; Goto and O'Donnell, 2001; Lansink et al., 2009; Gruber et al., 2009; van der Meer and Redish, 2011a). Furthermore, ventral striatal neurons participate in off-line "replay" events generated by the hippocampus (Pennartz et al., 2004; Lansink et al., 2008, 2009), and stimulation of the (ventral) hippocampus results in ventral striatum-mediated dopamine release (Blaha et al., 1997; Floresco et al., 2001). Thus, it is no surprise that ventral striatum would "inherit" phase precessing activity from hippocampal inputs.

In line with this inheritance scenario, van der Meer and Redish (2011a) found that theta phase precession in single ventral striatal neurons had striking similarities to phase precession in ventral CA3 neurons (Royer et al., 2010). In particular, ventral hippocampal cells start and end their phase precession $\sim 180$ degrees out of phase relative to dorsal hippocampal cells (Lubenov and Siapas, 2009; Royer et al., 2010); although van der Meer and Redish (2011a) did not record in ventral hippocampus, the phase precessing cells in ventral striatum precessed over the same theta phase range as ventral hippocampal cells (Supplementary Information in Royer et al. 2010). However, the strongly non-uniform distribution of ventral striatal phase precession across the track (van der Meer and Redish, 2011a) suggests that it may not be a verbatim copy of (ventral) hippocampal input ${ }^{18}$. Instead, the projection from hippocampus to ventral striatum may selectively

\footnotetext{
${ }^{18}$ It is notable that the subiculum, and especially its ventral aspect, is a major hippocampal source of ventral striatal inputs (Haber,
} 
emphasize or de-emphasize particular phase precessing inputs in a flexible manner, driven by dopaminergic modulation of synaptic plasticity; we discuss this "selective inheritance" idea in more detail in section 6. First, however, we situate it in the context of current thinking about the role of the hippocampal-ventral striatal projection in behavior.

\section{Functional contributions of hippocampal inputs to the ventral striatum}

\subsection{Context and place in the hippocampus}

The prevailing view on the role of hippocampal inputs to the ventral striatum is that information about place and context from the hippocampus modulates or gates ventral striatal contributions to behavior (Whishaw and Mittleman, 1991; Mizumori et al., 1999; Johnson et al., 2007; Gruber et al., 2009; Grace, 2010). Recording studies have demonstrated in rich detail that the hippocampus represents both location within a context and

the context itself (Figure 5). This idea is congruent with abundant, although not always straightforward to interpret, behavioral evidence that inactivations of the hippocampus (1) impair the ability to discriminate between contexts (Jeffery et al., 2004; Nadel, 2008; Maren, 2008), and (2) interfere with tasks that rely on location information, such as navigating to an allocentrically defined goal or home base (Redish and Touretzky, 1998; Whishaw et al., 2001; Jeffery and Etienne, 2004).

[Figure 5 about here.]

The debate about what exactly constitutes a context and under what conditions context vs. discrete cues dominate (e.g. Holland and Bouton 1999; Nadel 2008) is beyond the scope of this review. However, it is im2009; Sesack and Grace, 2010; Humphries and Prescott, 2010); yet, it is relatively under-studied in comparison to other hippocampal subfields. 
portant to point out that recent, converging evidence indicates context representations in the hippocampus are complex and dynamic - even changing while an animal is in a given environment. The hippocampus can treat two contexts as the same or different depending on training history (Leutgeb et al., 2005a; Fuhs and Touretzky, 2007; Colgin et al., 2010), currently active strategy (Rosenzweig et al., 2003; Eschenko and Mizumori, 2007; Jackson and Redish, 2007) and motivational state (Kennedy and Shapiro, 2009). Hippocampal context representations can switch after unsignaled changes in reinforcement contingencies (Smith and Mizumori, 2006; Fenton et al., 2010; Kelemen and Fenton, 2010) or perhaps most simply, between left and right runs on a linear track (McNaughton et al. 1983; see Figure 5b). To the extent that these hippocampal representations affect ventral striatal processing (an issue discussed below) it will be important to take into account an expanded notion of "context" as suggested by these hippocampal ensemble dynamics.

\subsection{Context and place gate ventral striatal processing}

The two distinct, but related views of hippocampal information representation - place and context - have resulted in similarly distinct, not mutually incompatible views of how this information may be used by the ventral striatum. The first view relies on representation of specific places within an environment. This is thought to be important in foraging settings, where animals need to learn and recall associations between particular places in an environment and rewards. Experimentally, a popular task that relies on this kind of association is conditioned place preference (CPP). In a representative setup, animals learn that a particular chamber within an environment is associated with reward, as exhibited by an increased amount of time spent at the rewarded location (the place preference). Using this type of setup, Ito et al. (2008) showed that a functional connection between the hippocampal formation and the ventral striatum (specifically, the nucleus accumbens shell) is required for $\mathrm{CPP}^{19}$. Rats with disconnection lesions showed reduced preference for the rewarded chamber of a multi-compartment apparatus. Similarly, Floresco et al. (1997) found that

\footnotetext{
${ }^{19}$ It is important to note that the hippocampal-dependence of CPP is not universal, but a function of the types of cues (discrete, contextual, internal) that can be used to define the preferred location; see e.g. Ferbinteanu and McDonald (2001).
} 
disconnection of vSub and vStr impaired rats' ability to collect rewards on the radial arm maze ${ }^{20}$. Thus, these studies offer direct support for a role of the HC-vStr projection in behavior requiring associations between places and rewards.

The second view of HC-vStr interactions is that representation of context in the hippocampus allows the ventral striatum to respond differentially not to context itself and to discrete cues with context-specific motivational relevance. This process does not use information about specific locations within an environment, but instead uses the identity of the context as a modulator or gate on ventral striatal processing. This type of arrangement is thought to underlie the role of hippocampal-ventral striatal interactions in context-specific drug sensitization and reinstatement (Crombag et al., 2008; Lodge and Grace, 2008), an important translationally relevant model to which we will return in more detail below. This role is conceptually similar to the role of the hippocampus in contextual fear conditioning, which is thought to rely on context representations in the hippocampus to modulate processing in the amygdala (Anagnostaras et al., 2001); a major difference is that the HC-vStr projection connects context representations to the mesolimbic dopamine pathway (Floresco et al., 2001; Grace, 2010; Sesack and Grace, 2010), a possible avenue for hippocampal context representations to powerfully modulate learning and behavior. Studies documenting the "gating" or "switching" effects of hippocampal inputs on individual ventral striatal neurons (O’Donnell and Grace, 1995; Mulder et al., 1998; Goto and Grace, 2008) provide elements of a physiological implementation of this idea.

Most relevant to context-dependent interactions between the hippocampus and the ventral striatum is the phenomenon of context-dependent reinstatement or relapse (Crombag et al., 2008). In an illustrative setup, the subject (typically a rodent) learns to lever-press for an appetitive reward in context A. Upon transferring the animal to a novel and distinct context B, some nonzero amount of lever-pressing is observed; however, in context B lever presses are not rewarded, and lever pressing will extinguish. When the animal is returned to

\footnotetext{
${ }^{20} \mathrm{~A}$ surprising result in this study is that on a delayed version of the task, HC-vStr disconnections no longer impaired performance, even though both bilateral HC and bilateral vStr lesions separately did result in impairments. As noted by the authors, a possibility is that the recruitment of mPFC in the delayed task allows for an indirect functional connection between HC and vStr through the mPFC.
} 
context A, lever pressing is reinstated or renewed. This scenario is similar to what in the addiction literature is referred to as "relapse", which represents a serious limitation to many current treatments of substance dependence. These may initially appear successful - mirroring the extinction phase in context-dependent reinstatement - but in general there is substantial incidence of relapse, to which contextual cues are thought to be a contributing factor (Conklin, 2006). The role of the ventral striatum in driving the reinstatement for drug rewards is well established in a number of settings, including relapse driven by context (Crombag et al., 2002; Bossert et al., 2007; Chaudhri et al., 2010). Given the context-dependence of reinstatement and relapse, a likely source of contextual information is the hippocampus. In support of this idea, lesions of the dorsal hippocampus interfere with the context-dependent reinstatement of cocaine seeking (Fuchs et al., 2005). The ventral hippocampus, including the ventral subiculum, is also implicated in reinstatement for drug rewards (Vorel et al., 2001; Rogers and See, 2007), an effect that may be context-dependent (Lasseter et al., 2010). Thus, noting caveats that testing for effects of context is not always straightforward (Holland and Bouton, 1999; Nadel, 2008; Maren, 2008), there is evidence that context-dependent reinstatement and relapse depends on an interaction between the hippocampus and the ventral striatum.

The above view conceptualizes the HC-vStr interaction as a conditioned association between places (in HC) and rewards (in ventral striatum), or context (in HC) and rewards. There is however also evidence that the HC-vStr projection plays a role in unconditioned behaviors. Given the connectivity of the ventral hippocampus with brain areas involved in unconditioned defensive behaviors and discrete cue associations, the effects of ventral hippocampal inactivation or stimulation are likely not exclusively context-specific (Bannerman et al., 2004). For instance, stimulation of the ventral hippocampus leads to a general increase in locomotor activity, an effect that can be prevented by inactivation of the ventral striatum (Lodge and Grace, 2008). Thus, the known role of the ventral hippocampus in mediating general, rather than context- or place-specific affective states, suggests that hippocampal inputs to ventral striatum likely include not only context or place information but also information reflecting the animal's current motivational state. This view raises an interesting disconnect: almost without exception, the recording work on which the "place/context" view of the hippocampus is based, has been done in the dorsal hippocampus. Compared to ventral hippocampal areas, the 
dorsal hippocampus sends relatively minor projections to the ventral striatum; future work in this direction is required to establish if the hippocampally-centered view that the ventral areas are less spatial/contextual, and the subcortically-centered view that hippocampal inputs are a source of spatial/contextual information, are compatible.

\section{Possible relevance of ventral striatal phase precession}

Leaving aside the gaps in our understanding of representation in ventral hippocampal areas, we are in a position to speculate about the possible relevance of ventral striatal phase precession. The discussion mirrors that of the earlier section outlining the reasons for interest in hippocampal phase precession, with its two broad answers: (1) ventral striatal phase precession is a useful tool, particularly for revealing cross-structure connectivity; and (2) it may be functionally important for coding, rapid learning, and/or planning.

\subsection{Ventral striatal phase precession as an experimental and theoretical tool}

With respect to phase precession as a tool, to the extent that phase precession is hippocampally derived (as argued in section 4.4) ventral striatal phase precession effectively "tags" ventral striatal neurons as receiv-

ing hippocampal input. Furthermore, because the properties of phase precession in the hippocampus - the subiculum excepted - are relatively well known, the specific pattern of phase precession in ventral striatum allows inferences about the likely source of the hippocampal input. For instance, imagine a random set of hippocampal neurons, with place fields and phase precession distributed over the task, were to provide input to a ventral striatal neuron (Figure 6a-b). In this scenario, the resulting phase precession pattern in the vStr neuron would look relatively disorganized (Figure 6b). Systematic phase precession up to the reward sites (van der Meer and Redish, 2011a) could not result from such a collection of random hippocampal inputs with 
distributed fields and phase precession; instead, such organization suggests inputs from a highly specific set of hippocampal neurons, perhaps as a result of reward-driven learning (Figure 6c). This is the "selective inheritance" idea (section 4.4). Thus, it would be of interest to track the development of ramping activity and phase precession in ventral striatal neurons on a spatial task, because this example illustrates that it might be possible to infer some properties of learning in hippocampal-ventral striatal synapses, which are known to exhibit LTP (Boeijinga et al., 1993).

[Figure 6 about here.]

Because the speed and range of phase precession in hippocampal place cells is readily extracted from the data, it seems possible to incorporate phase precession into a network model of hippocampal-ventral striatal projection. Such models could make quantitative predictions of what output patterns of phase precession would result from particular input distributions; especially when inputs from multiple areas are combined, which may be precessing at different rates and phases (Lubenov and Siapas, 2009; Royer et al., 2010) the output may not be intuitive. From a functional perspective, such models could test how particular learning rules (such as spike-timing and/or dopamine-dependent rules proposed for the striatum; Houk et al. 1995; Izhikevich 2007) might support the proposed reinforcement learning functions of the ventral striatum. By using spatial tasks, the phase precession effect can be exploited to reveal the dynamic relationship between place and context signals in the hippocampus and reward-related signals in the ventral striatum.

\subsection{Rapid learning and ventral striatal phase precession}

With respect to the possible functional importance of ventral striatal phase precession, we consider the same three possibilities supported by hippocampal phase precession: rapid sequence learning, phase coding, and planning or lookahead. 
A translation of the rapid learning view applied to vStr would hold that vStr phase precession contributes to changes in the efficacy of $\mathrm{HC}$ synapses onto that particular neuron ${ }^{21}$. As with intra-hippocampal phase precession, in this scenario cross-structure phase precession, by virtue of sequence compression and repetition with theta cycles, would lead to rapid encoding of experience. In other words, those HC neurons that phase precess with the appropriate time delay and speed will increase their synaptic strength onto the vStr neuron more rapidly than without phase precession. This would require the existence of an appropriately spike timing-dependent modulation of synaptic strength; it is known that the HC-vStr pathway exhibits NMDAR-dependent LTP (Boeijinga et al., 1993) but to our knowledge there has been no demonstration of spike-timing dependent plasticity (STDP).

A rapid-learning role for ventral striatal phase precession is of relevance to acquisition of place-reward and context-reward associations. Recall that the hippocampus appears to code both contexts and locations within it by activating a unique combination of place cells to each location (section 5.1 and Figure 5). As an animal moves through a particular environment (spatial context), phase precession ensures that place cells representing nearby locations are bound together through STDP (section 2.2). Ventral striatal phase precession suggests that anticipatory "ramp" neurons participate in these sequences, and thus that hippocampal place and context representations become associated with ventral striatal ramp neurons. For this scenario to work, the ventral striatal neuron would have to be appropriately theta-modulated already, even before learning has taken place. A possibility for realizing this is that some vStr neurons receive a baseline amount of input sufficient to generate theta modulation and/or phase precession, leaving room to modulate synaptic strength up and down in an experience-dependent manner. As discussed in section 4.4, there are a number of possible inputs that could provide such a signal; however, the real test would be to ask whether ventral striatal neurons are theta-modulated or even phase precessing before learning of place- or context-reward associations has taken place.

\footnotetext{
${ }^{21}$ By analogy to hippocampal subfield CA3 and its recurrent connections, we might entertain the possibility that phase precession contributes to intra-vStr plasticity; however, given the very different nature of MSN-MSN and FSI-MSN interactions (see e.g. Berke (2011) for a recent review) compared to the hippocampus, this seems far-fetched at this time. A first step in this direction would be to establish whether ventral striatal phase precessing neurons form coherent theta sequences.
} 
How might this rapid-learning role for ventral striatal phase precession elucidate the mechanisms underlying context-dependent reinstatement? Notably, a single pairing of context and drug reward is sufficient to evoke long-lasting context-dependent relapse (Ciccocioppo et al., 2004). This is suggestive of a rapid encoding and storage process of the kind that phase precession has been proposed to enable (section 3). Furthermore, using a procedure similar to context-dependent relapse, context-dependent sensitization to cocaine, Koya et al. (2009) demonstrated that sensitization in a particular context is mediated by a sparse population of ventral striatal neurons: selectively inactivating those neurons that were activated in a specific context abolished sensitization in that context. Thus, context-specific neural ensembles linked to particular behaviors form in the ventral striatum; given the role of the hippocampus in mediating such context-specific behavior in related settings, it is tempting to speculate that these ventral striatal ensembles reflect a conjunction of context-specific hippocampal input and the action of cocaine. Thus, the effects of cocaine (and other drugs susceptible to contextual reinstatement) on phase precessing ventral striatal neurons will be informative; in addition, how the hippocampus represents contexts under different conditions will likely impact ventral striatum and context-dependent reinstatement in particular.

\subsection{Rate and phase codes in the ventral striatum}

Phase precession in ventral striatum raises the possibility that distinct neural codes may be carried by firing rate and phase. The data in van der Meer and Redish (2011a) are consistent with a phase code for distance to a reward site, and a parallel rate code for expected (discounted) reward value. Recording studies observing rate and theta phase in the ventral striatal neurons as reward value is manipulated could test this idea. As noted by theoretical studies of phase coding (e.g. Jensen 2001; Nadasdy 2009 in a hippocampal context), phase codes can only be read out with access to the local field potential that was used for encoding. Thus, in

the case of a ventral striatal ramp cell, a decoder would only know whether a given spike indicated a short or long distance to reward if it also knew the phase of that spike. Since a theta LFP is present in the ventral striatum, and is typically coherent with the hippocampal LFP (see section 4.4), this information is locally 
available in principle. Evidence that ventral striatal neurons, or downstream targets of the ventral striatum, can use this information is not yet available; future work along the lines of showing that the probability of a postsynaptic spike depends on the theta phase of input or stimulation (as has been demonstrated in the hippocampus) would be proof of principle, constituting a phase-sensitive decoder.

Interestingly, there is independent evidence from human studies that the theta phase of ventral striatal activity contains information. Cohen et al. (2009a) recorded local field potentials from the human nucleus accumbens with $8-12 \mathrm{~Hz}$ oscillations as well as bursts of gamma oscillations $(40-80 \mathrm{~Hz}$, as occurs in the rat ventral striatum; see van der Meer et al. 2010b for review). It was found that the $8-12 \mathrm{~Hz}$ phase at which these gamma oscillations occurred was different between rewarded and unrewarded trials, and that breakdown in this phase relationship predicted strategy changes (Cohen et al., 2009b). Thus, although the mechanism by which theta phase coding in the ventral striatum might contribute to behavior is unclear, the data indicate that across species and experimental settings, theta phase coding is relevant to ventral striatal information processing.

\subsection{Phase precession and lookahead}

Phase precession implies sequence compression within a theta cycle that can be interpreted as retrospective or prospective activity, potentially useful for decision-making. It is currently not known whether ventral striatal phase precessing cells participate in coherent theta sequences, either within multiple simultaneously recorded ventral striatal cells, or in concert with hippocampal inputs. In support of the possibility that they might, however, Lansink et al. (2009) found that during off-line replay, theta-modulated neurons in ventral striatum were activated at the expected time based on their firing field relative to hippocampal place cells. If this sequential structure is preserved during ongoing behavior, it would mean that theta sequences consist of not just place information alone, but are enriched with a reward-related representation, well positioned to 
modulate behavior ${ }^{22}$.

[Figure 7 about here.]

To illustrate this idea, Figure 7 shows two schematic hippocampal place cell sequences straddling a T-maze choice point. The first sequence, $\mathrm{ABCD}$, leads to the unrewarded side of the maze, and does not activate the ventral striatal ramp neuron. The second sequence, $\mathrm{ABEF}$, leads to the rewarded side, activating the ventral striatal ramp neuron. Downstream structures that can relate the activity of this neuron to the upcoming place that generated it could then bias behavior in this direction. Of course, for this type of mechanism to work, a previous association between the ABEF sequence and the ramp cell would have to have been established. However, this does not mean that lookahead is not useful: for instance, to the extent that ventral striatal ramp neurons reflect current (rather than past) motivational state, ramp neurons could provide an on-line evaluation of a potential outcome, as required in so-called "model-based" decision making that is not tied to cached values reflecting past reward values (Dayan and Balleine, 2002; Daw et al., 2005; Niv et al., 2006). Moreover, this conception of ventral striatum mediating the influence of internally generated potential outcomes (“internal cues”; O’Reilly and Frank 2006; Zilli and Hasselmo 2008) is congruent with its known role in energizing and directing behavior in response to motivationally relevant external (discrete) cues (van der Meer and Redish, 2010).

\section{Conclusion}

In our review of the hippocampal literature on phase precession, we have distinguished three main proposals about its functional relevance: phase coding, lookahead, and rapid learning. The fact that phase precession occurs robustly in the medial prefrontal cortex and the ventral striatum suggests that these ideas have rele-

\footnotetext{
${ }^{22}$ Lansink et al. also found non-theta modulated neurons in the ventral striatum that exhibited coordinated reactivation with the hippocampus; we predict that such relationships are formed more slowly than those with theta-modulated neurons.
} 
vance beyond the hippocampus. In particular, the ventral striatum is a major output pathway through which the hippocampus can influence learning and ongoing behavior. Behaviors such as conditioned place preference and context-dependent relapse depend on interactions between the hippocampus and ventral striatum; in these settings, we have shown that the necessary ingredients are in place for phase precession to have an impact. Furthermore, using the idea of selective inheritance, phase precession can be a useful tool to reveal informative details about the inputs to particular phase precessing neurons, opening the door for the targeted investigation of how place-reward and context-reward associations are formed and used during behavior.

[Table 1 about here.]

Given that it is still early days for experimental reports on extrahippocampal phase precession, many of the ideas outlined in the second half of this paper are necessarily speculative. However, we believe these ideas illustrate the potential for phase precession to elucidate the mechanistic basis of how the hippocampal formation interacts with downstream structures. Our hope is that this collection of ideas will stimulate future work in this area; to this end, we present a summary of major open questions in Table 1.

\section{Acknowledgements}

The authors are indebted to Tobias Bast, Anoopum Gupta, Nathan Insel, Rutsuko Ito, Carien Lansink, A. David Redish, and Thilo Womelsdorf for their insightful comments on an earlier draft of the manuscript, and thank Chris Eliasmith, Kari Hoffman, L. Stan Leung, Tiago Maia, Yan Wu, and John Yeomans for discussion. MvdM is supported by the Canada Research Chairs program through the National Science and Engineering Research Council (NSERC, Tier II), VENI award 863.10.013 from the Netherlands Organisation for Scientific Research (NWO) and the University of Waterloo. 


\section{References}

Addante, R. J., Watrous, A. J., Yonelinas, A. P., Ekstrom, A. D., and Ranganath, C. (2011). Prestimulus theta activity predicts correct source memory retrieval. Proceedings of the National Academy of Sciences of the United States of America, 108(26):10702-7.

Alvernhe, A., Van Cauter, T., Save, E., and Poucet, B. (2008). Different CA1 and CA3 representations of novel routes in a shortcut situation. Journal of Neuroscience, 28(29):7324-33.

Amaral, D. G. and Lavenex, P. (2006). Hippocampal Neuroanatomy. In Andersen, P., Morris, R., Amaral, D., Bliss, T., and O’Keefe, J., editors, The hippocampus book. Oxford University Press.

Anagnostaras, S. G., Gale, G. D., and Fanselow, M. S. (2001). Hippocampus and contextual fear conditioning: recent controversies and advances. Hippocampus, 11(1):8-17.

Apicella, P., Ljungberg, T., Scarnati, E., and Schultz, W. (1991). Responses to reward in monkey dorsal and ventral striatum. Exp Brain Res, 85(3):491-500.

Bannerman, D. M., Rawlins, J. N. P., McHugh, S. B., Deacon, R. M. J., Yee, B. K., Bast, T., Zhang, W.-N., Pothuizen, H. H. J., and Feldon, J. (2004). Regional dissociations within the hippocampus-memory and anxiety. Neuroscience and Biobehavioral Reviews, 28(3):273-83.

Bast, T. (2007). Toward an integrative perspective on hippocampal function: from the rapid encoding of experience to adaptive behavior. Reviews in the Neurosciences, 18:253--281.

Bast, T. (2011). The hippocampal learning-behavior translation and the functional significance of hippocampal dysfunction in schizophrenia. Current Opinion in Neurobiology, 21(3):501-492.

Bast, T. and Feldon, J. (2003). Hippocampal modulation of sensorimotor processes. Progress in Neurobiology, 70(4):319-345.

Battaglia, F. P., Benchenane, K., Sirota, A., Pennartz, C. M. a., and Wiener, S. I. (2011). The hippocampus: hub of brain network communication for memory. Trends in Cognitive Sciences, 15(7):310-318.

Beck, A., Schlagenhauf, F., Wüstenberg, T., Hein, J., Kienast, T., Kahnt, T., Schmack, K., Hägele, C., Knutson, B., Heinz, A., and Wrase, J. (2009). Ventral striatal activation during reward anticipation correlates with impulsivity in alcoholics. Biological Psychiatry, 66(8):734-42.

Benchenane, K., Peyrache, A., Khamassi, M., Tierney, P. L., Gioanni, Y., Battaglia, F. P., and Wiener, S. I. (2010). Coherent theta oscillations and reorganization of spike timing in the hippocampal- prefrontal network upon learning. Neuron, 66(6):921-36.

Berens, P., Ecker, A. S., Gerwinn, S., Tolias, A. S., and Bethge, M. (2011). Reassessing optimal neural population codes with neurometric functions. Proceedings of the National Academy of Sciences of the United States of America, 108(11):4423-8.

Berens, P., Keliris, G. A., Ecker, A. S., Logothetis, N. K., and Tolias, A. S. (2008). Feature selectivity of the gamma-band of the local field potential in primate primary visual cortex. Front Neurosci, 2(2):199-207.

Berke, J. D. (2009). Fast oscillations in cortical-striatal networks switch frequency following rewarding events and stimulant drugs. 
European Journal of Neuroscience, 30(5):848-59.

Berke, J. D. (2011). Functional properties of striatal fast-spiking interneurons. Frontiers in Systems Neuroscience, 5(45):1—-7.

Berke, J. D., Okatan, M., Skurski, J., and Eichenbaum, H. B. (2004). Oscillatory Entrainment of Striatal Neurons in Freely-Moving Rats. Neuron, 43(6):883-896.

Berridge, K. (2007). The debate over dopamine s role in reward : the case for incentive salience. Psychopharmacology, 191(3):391431.

Bi, G. and Poo, M. (1998). Synaptic modifications in cultured hippocampal neurons: Dependence on spike timing, synaptic strength, and postsynaptic cell type. Journal of Neuroscience, 18(24):10464-10472.

Blaha, C. D., Yang, C. R., Floresco, S. B., Barr, A. M., and Phillips, A. G. (1997). Stimulation of the ventral subiculum of the hippocampus evokes glutamate receptor-mediated changes in dopamine efflux in the rat nucleus accumbens. European Journal of Neuroscience, 9(5):902-11.

Blair, H. T., Gupta, K., and Zhang, K. (2008). Conversion of a phase- to a rate-coded position signal by a three-stage model of theta cells, grid cells, and place cells. Hippocampus, 18(12):1239-55.

Bland, B. H. and Oddie, S. D. (2001). Theta band oscillation and synchrony in the hippocampal formation and associated structures: the case for its role in sensorimotor integration. Behavioural Brain Research, 127(1-2):119-36.

Blumenthal, A., Steiner, A., Seeland, K., and David Redish, A. (2011). Effects of pharmacological manipulations of NMDAreceptors on deliberation in the Multiple-T task. Neurobiology of Learning and Memory, 95(3):376-84.

Boeijinga, P. H., Mulder, A. B., Pennartz, C. M., Manshanden, I., and Lopes da Silva, F. H. (1993). Responses of the nucleus accumbens following fornix/fimbria stimulation in the rat. Identification and long-term potentiation of mono- and polysynaptic pathways. Neuroscience, 53(4):1049-58.

Bornstein, A. M. and Daw, N. D. (2011). Multiplicity of control in the basal ganglia: computational roles of striatal subregions. Current Opinion in Neurobiology, 21(3):374-80.

Bose, A. and Recce, M. (2001). Phase precession and phase-locking of hippocampal pyramidal cells. Hippocampus, 11(3):204-15.

Bossert, J. M., Poles, G. C., Wihbey, K. A., Koya, E., and Shaham, Y. (2007). Differential effects of blockade of dopamine D1family receptors in nucleus accumbens core or shell on reinstatement of heroin seeking induced by contextual and discrete cues. Journal of Neuroscience, 27(46):12655-63.

Brandon, M. P., Bogaard, A. R., Libby, C. P., Connerney, M. a., Gupta, K., and Hasselmo, M. E. (2011). Reduction of theta rhythm dissociates grid cell spatial periodicity from directional tuning. Science, 332(6029):595-9.

Brog, J., Salyapongse, A., Deutch, A., and Zahm, D. (1993). The patterns of afferent innervation of the core and shell in the Accumbens part of the rat ventral striatum: Immunohistochemical detection of retrogradely transported. The Journal of Comparative Neurology, 338:255-278.

Burgess, N., Barry, C., and O’Keefe, J. (2007). An oscillatory interference model of grid cell firing. Hippocampus, 17(9):801-12. 
Burgess, N. and O'Keefe, J. (2011). Models of place and grid cell firing and theta rhythmicity. Current Opinion in Neurobiology.

Burton, B. G., Hok, V., Save, E., and Poucet, B. (2009). Lesion of the ventral and intermediate hippocampus abolishes anticipatory activity in the medial prefrontal cortex of the rat. Behavioural brain research, 199(2):222-34.

Buzsáki, G. (2002). Theta oscillations in the hippocampus. Neuron, 33(3):325-40.

Buzsáki, G. (2005). Theta rhythm of navigation: link between path integration and landmark navigation, episodic and semantic memory. Hippocampus, 15(7):827-40.

Buzsáki, G., Leung, L. W., and Vanderwolf, C. H. (1983). Cellular bases of hippocampal \{EEG\} in the behaving rat. Brain Research, 287(2):139-171.

Cardinal, R. N., Parkinson, J. A., Hall, J., and Everitt, B. J. (2002). Emotion and motivation: The role of the amygdala, ventral striatum, and prefrontal cortex. Neuroscience and Biobehavioral Reviews, 26:321-352.

Carelli, R. M. and Deadwyler, S. A. (1994). A comparison of nucleus accumbens neuronal firing patterns during cocaine selfadministration and water reinforcement in rats. Journal of Neuroscience, 14(12):7735-7746.

Carelli, R. M., Ijames, S., and Crumling, A. (2000). Evidence that separate neural circuits in the nucleus accumbens encode cocaine versus natural (water and food) reward. Journal of Neuroscience, 20(11):4255-4266.

Chaudhri, N., Sahuque, L. L., Schairer, W. W., and Janak, P. H. (2010). Separable roles of the nucleus accumbens core and shell in context- and cue-induced alcohol-seeking. Neuropsychopharmacology, 35(3):783-91.

Cheng, S. and Frank, L. M. (2008). New experiences enhance coordinated neural activity in the hippocampus. Neuron, 57(2):30313.

Ciccocioppo, R., Martin-Fardon, R., and Weiss, F. (2004). Stimuli associated with a single cocaine experience elicit long-lasting cocaine-seeking. Nature Neuroscience, 7(5):495-6.

Cohen, M. X., Axmacher, N., Lenartz, D., Elger, C. E., Sturm, V., and Schlaepfer, T. E. (2009a). Good vibrations: cross-frequency coupling in the human nucleus accumbens during reward processing. J Cogn Neurosci, 21(5):875-889.

Cohen, M. X., Axmacher, N., Lenartz, D., Elger, C. E., Sturm, V., and Schlaepfer, T. E. (2009b). Nuclei accumbens phase synchrony predicts decision-making reversals following negative feedback. Journal of Neuroscience, 29(23):7591-8.

Colgin, L. L., Denninger, T., Fyhn, M., Hafting, T., Bonnevie, T., Jensen, O., Moser, M.-B., and Moser, E. I. (2009). Frequency of gamma oscillations routes flow of information in the hippocampus. Nature, 462(7271):353-357.

Colgin, L. L., Leutgeb, S., Jezek, K., Leutgeb, J. K., Moser, E. I., McNaughton, B. L., and Moser, M.-B. (2010). Attractor-map versus autoassociation based attractor dynamics in the hippocampal network. Journal of Neurophysiology, 104(1):35-50.

Conklin, C. A. (2006). Environments as cues to smoke: implications for human extinction-based research and treatment. Experimental and Clinical Psychopharmacology, 14(1):12-9.

Corbit, L. H., Ostlund, S. B., and Balleine, B. W. (2002). Sensitivity to instrumental contingency degradation is mediated by the entorhinal cortex and its efferents via the dorsal hippocampus. J. Neurosci., 22:10976-10984. 
Crombag, H. S., Bossert, J. M., Koya, E., and Shaham, Y. (2008). Context-induced relapse to drug seeking: a review. Philosophical transactions of the Royal Society of London. Series B, Biological sciences, 363(1507):3233-43.

Crombag, H. S., Grimm, J. W., and Shaham, Y. (2002). Effect of dopamine receptor antagonists on renewal of cocaine seeking by reexposure to drug-associated contextual cues. Neuropsychopharmacology, 27(6):1006-15.

Cromwell, H. C., Hassani, O. K., and Schultz, W. (2005). Relative reward processing in primate striatum. Experimental Brain Research, 162(4):520-5.

Cromwell, H. C. and Schultz, W. (2003). Effects of expectations for different reward magnitudes on neuronal activity in primate striatum. Journal of Neurophysiology, 89(5):2823-2838.

Daw, N. D. (2003). Reinforcement learning models of the dopamine system and their behavioral implications. Ph.D. thesis, CMU.

Daw, N. D., Niv, Y., and Dayan, P. (2005). Uncertainty-based competition between prefrontal and dorsolateral striatal systems for behavioral control. Nature Neuroscience, 8:1704-1711.

Dayan, P. and Balleine, B. W. (2002). Reward, motivation and reinforcement learning. Neuron, 36:285-298.

de Almeida, L., Idiart, M., and Lisman, J. E. (2009). The input-output transformation of the hippocampal granule cells: from grid cells to place fields. Journal of Neuroscience, 29(23):7504-12.

Diba, K. and Buzsáki, G. (2008). Hippocampal network dynamics constrain the time lag between pyramidal cells across modified environments. Journal of Neuroscience, 28(50):13448-56.

Doeller, C. F., Barry, C., and Burgess, N. (2010). Evidence for grid cells in a human memory network. Nature, 463(7281):657-61.

Dragoi, G. and Buzsáki, G. (2006). Temporal encoding of place sequences by hippocampal cell assemblies. Neuron, 50(1):145-57.

Dragoi, G. and Tonegawa, S. (2010). Preplay of future place cell sequences by hippocampal cellular assemblies. Nature, 469(7330):397-401.

Ego-Stengel, V. and Wilson, M. A. (2007). Spatial selectivity and theta phase precession in CA1 interneurons. Hippocampus, 17(2):161-74.

Eichenbaum, H., Dudchenko, P., Wood, E., Shapiro, M., and Tanila, H. (1999). The hippocampus, memory, and place cells: is it spatial memory or a memory space? Neuron, 23(2):209-26.

Ekstrom, A. D., Caplan, J. B., Ho, E., Shattuck, K., Fried, I., and Kahana, M. J. (2005). Human hippocampal theta activity during virtual navigation. Hippocampus, 15(7):881-9.

Eschenko, O. and Mizumori, S. J. Y. (2007). Memory influences on hippocampal and striatal neural codes: effects of a shift between task rules. Neurobiology of Learning and Memory, 87(4):495-509.

Fanselow, M. S. and Dong, H.-W. (2010). Are the dorsal and ventral hippocampus functionally distinct structures? Neuron, 65(1):7-19.

Fenton, A. A., Lytton, W. W., Barry, J. M., Lenck-Santini, P.-P., Zinyuk, L. E., Kubík, S., Bures, J., Poucet, B., Muller, R. U., and Olypher, A. V. (2010). Attention-like modulation of hippocampus place cell discharge. Journal of Neuroscience, 30(13):4613-25. 
Ferbinteanu, J. and McDonald, R. J. (2001). Dorsal/ventral hippocampus, fornix, and conditioned place preference. Hippocampus, 11(2):187-200.

Finch, D. (1996). Neurophysiology of converging synaptic inputs from the rat prefrontal cortex, amygdala, midline thalamus, and hippocampal formation onto single neurons of the caudate/putamen and nucleus accumbens. Hippocampus, 6(5):495-512.

Floresco, S. B., Seamans, J. K., and Phillips, A. G. (1997). Selective Roles for hippocampal, prefrontal cortical, and ventral striatal circuits in radial-arm maze tasks with or without a delay. Journal of Neuroscience, 17(5):1880-1890.

Floresco, S. B., Todd, C. L., and Grace, A. A. (2001). Glutamatergic afferents from the hippocampus to the nucleus accumbens regulate activity of ventral tegmental area dopamine neurons. Journal of Neuroscience, 21(13):4915-4922.

Fortin, N. J., Agster, K. L., and Eichenbaum, H. B. (2002). Critical role of the hippocampus in memory for sequences of events. Nature Neuroscience, 5(5):458-62.

Foster, D. J. and Wilson, M. A. (2007). Hippocampal theta sequences. Hippocampus, 17(11):1093-9.

Fuchs, R. A., Evans, K. A., Ledford, C. C., Parker, M. P., Case, J. M., Mehta, R. H., and See, R. E. (2005). The role of the dorsomedial prefrontal cortex, basolateral amygdala, and dorsal hippocampus in contextual reinstatement of cocaine seeking in rats. Neuropsychopharmacology, 30(2):296-309.

Fuhs, M. C. and Touretzky, D. S. (2007). Context learning in the rodent hippocampus. Neural Computation, 19(12):3173-215.

Geisler, C., Diba, K., Pastalkova, E., Mizuseki, K., Royer, S., and Buzsáki, G. (2010). Temporal delays among place cells determine the frequency of population theta oscillations in the hippocampus. Proceedings of the National Academy of Sciences of the United States of America, 107(17):7957-7962.

Geisler, C., Robbe, D., Zugaro, M., Sirota, A., and Buzsáki, G. (2007). Hippocampal place cell assemblies are speed-controlled oscillators. Proceedings of the National Academy of Sciences of the United States of America, 104(19):8149-54.

Gelbard-Sagiv, H., Mukamel, R., Harel, M., Malach, R., and Fried, I. (2008). Internally generated reactivation of single neurons in human hippocampus during free recall. Science, 322(5898):96-101.

Ginther, M. R., Walsh, D. F., and Ramus, S. J. (2011). Hippocampal neurons encode different episodes in an overlapping sequence of odors task. Journal of Neuroscience, 31(7):2706-11.

Giocomo, L. M., Zilli, E. A., Fransén, E., and Hasselmo, M. E. (2007). Temporal frequency of subthreshold oscillations scales with entorhinal grid cell field spacing. Science, 315(5819):1719-22.

Goto, Y. and Grace, A. A. (2008). Limbic and cortical information processing in the nucleus accumbens. Trends in Neurosciences, 31(11):552-558.

Goto, Y. and O'Donnell, P. (2001). Synchronous activity in the hippocampus and nucleus accumbens in vivo. Journal of Neuroscience, 21(4):RC131.

Grace, A. A. (2010). Dopamine system dysregulation by the ventral subiculum as the common pathophysiological basis for schizophrenia psychosis, psychostimulant abuse, and stress. Neurotoxicity research, 18(3-4):367-76. 
Gray, J. A. and McNaughton, N. (2000). The Neuropsychology of anxiety: an enquiry into the functions of the septo-hippocampal system. Oxford: Oxford University Press, 2 edition.

Green, J. D. and Arduini, A. A. (1954). Hippocampal electrical activity in arousal. Neuroscience Letters.

Groenewegen, H., der Zee, E., Te Kortschot, A., and Witter, M. (1987). Organization of the projections from the subiculum to the ventral striatum in the rat. A study using anterograde transport of Phaseolus vulgaris leucoagglutinin. Neuroscience, 23(1):103120.

Groenewegen, H. J., Wright, C. I., Beijer, a. V., and Voorn, P. (1999). Convergence and segregation of ventral striatal inputs and outputs. Annals of the New York Academy of Sciences, 877:49-63.

Gruber, A. J., Hussain, R. J., and O’Donnell, P. (2009). The Nucleus Accumbens: A Switchboard for Goal-Directed Behaviors. PLoS ONE, 4(4):e5062.

Gupta, A. S., van der Meer, M. A. A., Touretzky, D. S., and Redish, A. D. (2010). Hippocampal replay is not a simple function of experience. Neuron, 65(5):695-705.

Gupta, A. S., van der Meer, M. A. A., Touretzky, D. S., and Redish, A. D. (2011). Hippocampal theta sequences : dynamic modulation and the segmentation of spatial experience. page submitted.

Haber, S. N. (2009). Anatomy and connectivity of the reward circuit. In Dreher, J.-C. and Tremblay, L., editors, Handbook of Reward and Decision Making, pages 3-27. Academic Press.

Hafting, T., Fyhn, M., Bonnevie, T., Moser, M.-B., and Moser, E. I. (2008). Hippocampus-independent phase precession in entorhinal grid cells. Nature, 453(7199):1248-52.

Hare, T. A., O'Doherty, J., Camerer, C. F., Schultz, W., and Rangel, A. (2008). Dissociating the role of the orbitofrontal cortex and the striatum in the computation of goal values and prediction errors. Journal of Neuroscience, 28(22):5623-5630.

Harris, K. D., Henze, D. a., Hirase, H., Leinekugel, X., Dragoi, G., Czurkó, A., and Buzsáki, G. (2002). Spike train dynamics predicts theta-related phase precession in hippocampal pyramidal cells. Nature, 417(6890):738-41.

Harvey, C. D., Collman, F., Dombeck, D. a., and Tank, D. W. (2009). Intracellular dynamics of hippocampal place cells during virtual navigation. Nature, 461(7266):941-6.

Hassani, O. K., Cromwell, H. C., and Schultz, W. (2001). Influence of expectation of different rewards on behavior-related neuronal activity in the striatum. Journal of Neurophysiology, 85(6):2477-89.

Hasselmo, M. E. (2005). What is the function of hippocampal theta rhythm?-Linking behavioral data to phasic properties of field potential and unit recording data. Hippocampus, 15(7):936-49.

Hebb, D. (1949). The Organization of Behavior. Wiley, New York, 911:112-126.

Hirase, H., Czurkó, A., Csicsvari, J., and Buzsáki, G. (1999). Firing rate and theta-phase coding by hippocampal pyramidal neurons during 'space clamping'. The European Journal of Neuroscience, 11(12):4373-80.

Holland, P. C. and Bouton, M. E. (1999). Hippocampus and context in classical conditioning. Current Opinion in Neurobiology, 
9(2):195-202.

Hollerman, J., Tremblay, L., and Schultz, W. (1998a). Influence of reward expectation on behavior-related neuronal activity in primate striatum. Journal of Neurophysiology, 80(2):947.

Hollerman, J. R., Tremblay, L., and Schultz, W. (1998b). Influence of Reward Expectation on Behavior-Related Neuronal Activity in Primate Striatum. J Neurophysiol, 80(2):947-963.

Hölscher, C., Anwyl, R., and Rowan, M. J. (1997). Stimulation on the positive phase of hippocampal theta rhythm induces longterm potentiation that can Be depotentiated by stimulation on the negative phase in area CA1 in vivo. Journal of Neuroscience, 17(16):6470-7.

Houk, J. C., Adams, J. L., and Barto, A. G. (1995). A model of how the basal ganglia generate and use neural signals that predict reinforcement. In J. C. Houk, J. L. Davis, \& D. G. Beiser (Eds.), Models of information processing in the basal ganglia, pages pp249-270.

Hu, H., Vervaeke, K., Graham, L. J., and Storm, J. F. (2009). Complementary theta resonance filtering by two spatially segregated mechanisms in CA1 hippocampal pyramidal neurons. The Journal of Neuroscience, 29(46):14472-83.

Huh, N., Jo, S., Kim, H., Sul, J. H., and Jung, M. W. (2009). Model-based reinforcement learning under concurrent schedules of reinforcement in rodents. Learning \& Memory, 16(5):315-23.

Humphries, M. and Prescott, T. (2010). The ventral basal ganglia, a selection mechanism at the crossroads of space, strategy, and reward. Progress in Neurobiology, 90(4):385-417.

Huxter, J., Burgess, N., and OKeefe, J. (2003). Independent rate and temporal coding in hippocampal pyramidal cells. Nature, 425(6960):828.

Huxter, J. R., Senior, T. J., Allen, K., and Csicsvari, J. (2008). Theta phase-specific codes for two-dimensional position, trajectory and heading in the hippocampus. Nature Neuroscience, 11(5):587-94.

Hyman, J. M., Hasselmo, M. E., and Seamans, J. K. (2011). What is the Functional Relevance of Prefrontal Cortex Entrainment to Hippocampal Theta Rhythms? Frontiers in Neuroscience, 5:24.

Hyman, J. M., Wyble, B. P., Goyal, V., Rossi, C. A., and Hasselmo, M. E. (2003). Stimulation in hippocampal region CA1 in behaving rats yields long-term potentiation when delivered to the peak of theta and long-term depression when delivered to the trough. Journal of Neuroscience, 23(37):11725-31.

Hyman, J. M., Zilli, E. A., Paley, A. M., and Hasselmo, M. E. (2010). Working Memory Performance Correlates with PrefrontalHippocampal Theta Interactions but not with Prefrontal Neuron Firing Rates. Frontiers in Integrative Neuroscience, 4:2.

Ikemoto, S. and Panksepp, J. (1999). The role of nucleus accumbens dopamine in motivated behavior: a unifying interpretation with special reference to reward-seeking. Brain Research Reviews, 31(1):6-41.

Ito, M. and Doya, K. (2011). Multiple representations and algorithms for reinforcement learning in the cortico-basal ganglia circuit. Current Opinion in Neurobiology, pages 1-6. 
Ito, R., Robbins, T., Pennartz, C., and Everitt, B. (2008). Functional interaction between the hippocampus and nucleus accumbens shell is necessary for the acquisition of appetitive spatial context conditioning. Journal of Neuroscience, 28(27):6950-6959.

Izhikevich, E. M. (2007). Solving the distal reward problem through linkage of STDP and dopamine signaling. Cerebral Cortex, 17(10):2443-52.

Jackson, J. and Redish, A. D. (2007). Network dynamics of hippocampal cell-assemblies resemble multiple spatial maps within single tasks. Hippocampus, 17(12):1209-29.

Jacobs, J., Kahana, M. J., Ekstrom, A. D., and Fried, I. (2007). Brain oscillations control timing of single-neuron activity in humans. Journal of Neuroscience, 27(14):3839-44.

Jay, T. M. and Witter, M. P. (1991). Distribution of hippocampal CA1 and subicular efferents in the prefrontal cortex of the rat studied by means of anterograde transport of Phaseolus vulgaris-leucoagglutinin. The Journal of Comparative Neurology, 313(4):574-86.

Jeewajee, A., Lever, C., Burton, S., O’Keefe, J., and Burgess, N. (2008). Environmental novelty is signaled by reduction of the hippocampal theta frequency. Hippocampus, 18(4):340-8.

Jeffery, K. J., Anderson, M. I., Hayman, R., and Chakraborty, S. (2004). A proposed architecture for the neural representation of spatial context. Neuroscience and Biobehavioral Reviews, 28(2):201-18.

Jeffery, K. J. and Etienne, A. S. (2004). Path Integration in Mammals. Hippocampus, 14:180-192.

Jensen, O. (2001). Information transfer between rhythmically coupled networks: reading the hippocampal phase code. Neural Computation, 13(12):2743-61.

Jensen, O. and Lisman, J. (1996). Hippocampal CA3 region predicts memory sequences: accounting for the phase precession of place cells. Learning \& Memory, 3(2-3):279.

Jensen, O. and Lisman, J. (2000). Position reconstruction from an ensemble of hippocampal place cells: contribution of theta phase coding. Journal of Neurophysiology, 83(5):2602.

Johnson, A. and Redish, A. D. (2007). Neural ensembles in ca3 transiently encode paths forward of the animal at a decision point. Journal of Neuroscience, 27(45):12176-12189.

Johnson, A., van der Meer, M. A. A., and Redish, A. D. (2007). Integrating hippocampus and striatum in decision-making. Curr Opin Neurobiol, 17(6):692-697.

Jones, M. W. and Wilson, M. a. (2005a). Phase precession of medial prefrontal cortical activity relative to the hippocampal theta rhythm. Hippocampus, 15(7):867-73.

Jones, M. W. and Wilson, M. A. (2005b). Theta rhythms coordinate hippocampal-prefrontal interactions in a spatial memory task. PLoS Biology, 3(12):e402.

Jung, M. W., Wiener, S. I., and McNaughton, B. L. (1994). Comparison of spatial firing characteristics of units in dorsal and ventral hippocampus of the rat. Journal of Neuroscience, 14(12):7347-56. 
Kahana, M. J., Seelig, D., and Madsen, J. R. (2001). Theta returns. Current Opinion in Neurobiology, 11(6):739-44.

Kamondi, A., Acsády, L., Wang, X. J., and Buzsáki, G. (1998). Theta oscillations in somata and dendrites of hippocampal pyramidal cells in vivo: activity-dependent phase-precession of action potentials. Hippocampus, 8(3):244-61.

Kelemen, E. and Fenton, A. A. (2010). Dynamic grouping of hippocampal neural activity during cognitive control of two spatial frames. PLoS Biology, 8(6):e1000403.

Kennedy, P. J. and Shapiro, M. L. (2009). Motivational states activate distinct hippocampal representations to guide goal-directed behaviors. Proceedings of the National Academy of Sciences of the United States of America, 106(26):10805-10.

Khamassi, M., Mulder, A., Tabuchi, E., Douchamps, V., and Wiener, S. (2008). Anticipatory reward signals in ventral striatal neurons of behaving rats. European Journal of Neuroscience, 28:1849-1866.

Kjelstrup, K. B., Solstad, T., Brun, V. H., Hafting, T., Leutgeb, S., Witter, M. P., Moser, E. I., and Moser, M.-B. (2008). Finite scale of spatial representation in the hippocampus. Science, 321(5885):140-3.

Klausberger, T., Magill, P. J., Márton, L. F., Roberts, J. D. B., Cobden, P. M., Buzsáki, G., and Somogyi, P. (2003). Brain-state and cell-type-specific firing of hippocampal interneurons in vivo. Nature, 421:844-848.

Kocsis, B., Di Prisco, G. V., and Vertes, R. P. (2001). Theta synchronization in the limbic system: the role of Gudden's tegmental nuclei. European Journal of Neuroscience, 13(2):381-388.

Kocsis, B. and Vertes, R. P. (1992). Dorsal raphe neurons: synchronous discharge with the theta rhythm of the hippocampus in the freely behaving rat. J Neurophysiol, 68(4):1463-1467.

Koenig, J., Linder, A. N., Leutgeb, J. K., and Leutgeb, S. (2011). The spatial periodicity of grid cells is not sustained during reduced theta oscillations. Science, 332(6029):592-5.

Koya, E., Golden, S. A., Harvey, B. K., Guez-Barber, D. H., Berkow, A., Simmons, D. E., Bossert, J. M., Nair, S. G., Uejima, J. L., Marin, M. T., Mitchell, T. B., Farquhar, D., Ghosh, S. C., Mattson, B. J., and Hope, B. T. (2009). Targeted disruption of cocaine-activated nucleus accumbens neurons prevents context-specific sensitization. Nature Neuroscience, 12(8):1069-73.

Lansink, C. S., Goltstein, P. M., Lankelma, J. V., Joosten, R. N. J. M. A., McNaughton, B. L., and Pennartz, C. M. A. (2008). Preferential reactivation of motivationally relevant information in the ventral striatum. Journal of Neuroscience, 28(25):63726382.

Lansink, C. S., Goltstein, P. M., Lankelma, J. V., McNaughton, B. L., and Pennartz, C. M. A. (2009). Hippocampus leads ventral striatum in replay of place-reward information. PLoS Biol, 7(8):e1000173.

Larson, J., Wong, D., and Lynch, G. (1986). Patterned stimulation at the theta frequency is optimal for the induction of hippocampal long-term potentiation. Brain Research, 368(2):347-350.

Lasseter, H. C., Xie, X., Ramirez, D. R., and Fuchs, R. A. (2010). Sub-region specific contribution of the ventral hippocampus to drug context-induced reinstatement of cocaine-seeking behavior in rats. Neuroscience, 171(3):830-9.

Lavoie, A. M. and Mizumori, S. J. Y. (1994). Spatial-, movement- and reward-sensitive discharge by medial ventral striatum neurons 
in rats. Brain Research, 638:157-168.

Leibold, C., Gundlfinger, A., Schmidt, R., Thurley, K., Schmitz, D., and Kempter, R. (2008). Temporal compression mediated by short-term synaptic plasticity. Proceedings of the National Academy of Sciences of the United States of America, 105(11):441722.

Lenck-Santini, P.-P. and Holmes, G. L. (2008). Altered phase precession and compression of temporal sequences by place cells in epileptic rats. Journal of Neuroscience, 28(19):5053-62.

Lengyel, M., Szatmáry, Z., and Erdi, P. (2003). Dynamically detuned oscillations account for the coupled rate and temporal code of place cell firing. Hippocampus, 13(6):700-14.

Leung, L. S. (1998). Generation of theta and gamma rhythms in the hippocampus. Neuroscience and Biobehavioral Reviews, 22(2):275-90

Leung, L. S. (2011). A Model of Intracellular Theta Phase Precession Dependent on Intrinsic Subthreshold Membrane Currents. Journal of Neuroscience, 31(34):12282-12296.

Leung, L. S. and Yim, C. Y. (1986). Intracellular records of theta rhythm in hippocampal CA1 cells of the rat. Brain research, 367(1-2):323-7.

Leung, L. S. and Yim, C. Y. (1993). Rhythmic delta-frequency activities in the nucleus accumbens of anesthetized and freely moving rats. Can J Physiol Pharmacol, 71(5-6):311-320.

Leung, L. S. and Yu, H. W. (1998). Theta-frequency resonance in hippocampal CA1 neurons in vitro demonstrated by sinusoidal current injection. Journal of Neurophysiology, 79(3):1592-6.

Leutgeb, J. K., Leutgeb, S., Treves, A., Meyer, R., Barnes, C. A., McNaughton, B. L., Moser, M.-B., and Moser, E. I. (2005a). Progressive transformation of hippocampal neuronal representations in "morphed" environments. Neuron, 48(2):345-58.

Leutgeb, S., Leutgeb, J., Barnes, C., and Moser, E. (2005b). Independent codes for spatial and episodic memory in hippocampal neuronal ensembles. Science, 309:619-623.

Lisman, J. and Redish, A. (2009). Prediction, sequences and the hippocampus. Philosophical transactions of the Royal Society of London. Series B, Biological sciences, 364(1521):1193-201.

Lodge, D. J. and Grace, A. A. (2008). Amphetamine activation of hippocampal drive of mesolimbic dopamine neurons: a mechanism of behavioral sensitization. Journal of Neuroscience, 28(31):7876-82.

Losonczy, A., Zemelman, B. V., Vaziri, A., and Magee, J. C. (2010). Network mechanisms of theta related neuronal activity in hippocampal CA1 pyramidal neurons. Nature Neuroscience, 13(8):967-72.

Lubenov, E. V. and Siapas, A. G. (2009). Hippocampal theta oscillations are travelling waves. Nature, 459(7246):534-9.

Magee, J. (2001). Dendritic mechanisms of phase precession in hippocampal CA1 pyramidal neurons. Journal of Neurophysiology, 86(1):528.

Manns, J. R., Zilli, E. A., Ong, K. C., Hasselmo, M. E., and Eichenbaum, H. (2007). Hippocampal CA1 spiking during encoding 
and retrieval: relation to theta phase. Neurobiology of Learning and Memory, 87(1):9-20.

Maren, S. (2008). Pavlovian fear conditioning as a behavioral assay for hippocampus and amygdala function: cautions and caveats.

The European Journal of Neuroscience, 28(8):1661-6.

Martin, P. D. (2001). Locomotion towards a goal alters the synchronous firing of neurons recorded simultaneously in the subiculum and nucleus accumbens of rats. Behavioral Brain Research, 124(1):19-28.

Martin, P. D. and Ono, T. (2000). Effects of reward anticipation, reward presentation, and spatial parameters on the firing of single neurons recorded in the subiculum and nucleus accumbens of freely moving rats. Behavioural Brain Research, 116(1):23-38.

Masquelier, T., Hugues, E., Deco, G., and Thorpe, S. J. (2009). Oscillations, phase-of-firing coding, and spike timing-dependent plasticity: an efficient learning scheme. Journal of Neuroscience, 29(43):13484-93.

Maurer, A. P., Burke, S. N., Lipa, P., Skaggs, W. E., and Barnes, C. a. (2011). Greater running speeds result in altered hippocampal phase sequence dynamics. Hippocampus, 000.

Maurer, A. P., Cowen, S. L., Burke, S. N., Barnes, C. a., and McNaughton, B. L. (2006). Phase precession in hippocampal interneurons showing strong functional coupling to individual pyramidal cells. Journal of Neuroscience, 26(52):13485-92.

Maurer, A. P. and McNaughton, B. L. (2007). Network and intrinsic cellular mechanisms underlying theta phase precession of hippocampal neurons. Trends in Neurosciences, 30(7):325-33.

McNaughton, B., Barnes, C., and O'keefe, J. (1983). The contributions of position, direction, and velocity to single unit activity in the hippocampus of freely-moving rats. Experimental Brain Research, 52(1):41-49.

Mehta, M. R., Barnes, C. A., and McNaughton, B. L. (1997). Experience-dependent, asymmetric expansion of hippocampal place fields. Proceedings of the National Academy of Sciences of the United States of America, 94(16):8918-21.

Mehta, M. R., Lee, A. K., and Wilson, M. A. (2002). Role of experience and oscillations in transforming a rate code into a temporal code. Nature, 417(6890):741-6.

Miyazaki, K., Mogi, E., Araki, N., and Matsumoto, G. (1998). Reward-quality dependent anticipation in rat nucleus accumbens. NeuroReport, 9(17):3943-3948.

Mizumori, S. J. Y., Pratt, W. E., and Ragozzino, K. E. (1999). Function of the nucleus accumbens within the context of the larger striatal system. Psychobiology, 27(2):214-224.

Mizuseki, K., Sirota, A., Pastalkova, E., and Buzsáki, G. (2009). Theta oscillations provide temporal windows for local circuit computation in the entorhinal-hippocampal loop. Neuron, 64(2):267-80.

Mogenson, G. J. and Yang, C. R. (1991). The contribution of basal forebrain to limbic-motor integration and the mediation of motivation to action. Advances in Experimental Medicine and Biology, 295:267-90.

Morris, R. G. M. (2006). Theories of hippocampal function. In Andersen, P., Morris, R., Amaral, D., Bliss, T., and O’Keefe, J., editors, The hippocampus book. Oxford University Press.

Morris, R. G. M., Garrud, P., Rawlins, J. N. P., and O’keefe, J. (1982). Place navigation impaired in rats with hippocampal lesions. 
Nature, 297:681-683.

Moser, M. B. and Moser, E. I. (1998). Functional differentiation in the hippocampus. Hippocampus, 8(6):608-19.

Mulder, A. B., Hodenpijl, M. G., and da Silva, F. H. L. (1998). Electrophysiology of the hippocampal and amygdaloid projections to the nucleus accumbens of the rat: convergence, segregation, and interaction of inputs. Journal of Neuroscience, 18(13):50955102.

Mulder, A. B., Shibata, R., Trullier, O., and Wiener, S. I. (2005). Spatially selective reward site responses in tonically active neurons of the nucleus accumbens in behaving rats. Experimental Brain Research, 163:32-43.

Nadasdy, Z. (2009). Information encoding and reconstruction from the phase of action potentials. Frontiers in Systems Neuroscience, $3(6): 1-20$.

Nadel, L. (2008). The hippocampus and context revisited. In Mizumori, S. J. Y., editor, Hippocampal Place Fields: Relevance to Learning and Memory, pages 3-15.

Navratilova, Z., Giocomo, L. M., Fellous, J.-M., Hasselmo, M. E., and McNaughton, B. L. (2011). Phase precession and variable spatial scaling in a periodic attractor map model of medial entorhinal grid cells with realistic after-spike dynamics. Hippocampus.

Nicola, S. M. (2007). The nucleus accumbens as part of a basal ganglia action selection circuit. Psychopharmacology (Berl), 191(3):521-550.

Niv, Y., Joel, D., and Dayan, P. (2006). A normative perspective on motivation. Trends Cogn Sci, 10(8):375-381.

O'Doherty, J. P., Hampton, A., and Kim, H. (2007). Model-based fMRI and its application to reward learning and decision making. Annals of the New York Academy of Sciences, 1104:35-53.

O’Donnell, P. and Grace, A. (1995). Synaptic Interactions Accumbens Neurons : Input among Excitatory Afferents to Nucleus Hippocampal Gating of Prefrontal Cortical. Journal of Neuroscience, 15:3622-3639.

O'Donnell, P. and Grace, A. A. (1993). Physiological and morphological properties of accumbens core and shell neurons recorded in vitro. Synapse, 13(2):135-60.

O’Keefe, J. (1993). Hippocampus, theta, and spatial memory. Current Opinion in Neurobiology, 3(6):917-924.

O'Keefe, J. and Burgess, N. (1999). Theta activity, virtual navigation and the human hippocampus. Trends in Cognitive Sciences, 3(11):403-406.

O'Keefe, J. and Burgess, N. (2005). Dual phase and rate coding in hippocampal place cells: theoretical significance and relationship to entorhinal grid cells. Hippocampus, 15(7):853-66.

O’Keefe, J. and L, N. (1978). The hippocampus as a cognitive map. Oxford: Clarendon. Paxinos, G., \& Watson, C.

O'Keefe, J. and Recce, M. L. (1993). Phase relationship between hippocampal place units and the EEG theta rhythm. Hippocampus, 3(3):317-30.

O'Keefe, J. and Speakman, A. (1987). Single unit activity in the rat hippocampus during a spatial memory task. Experimental Brain Research, 68:1-27. 
O’Reilly, R. C. and Frank, M. J. (2006). Making working memory work: a computational model of learning in the prefrontal cortex and basal ganglia. Neural Computation, 18(2):283-328.

Panzeri, S., Brunel, N., Logothetis, N. K., and Kayser, C. (2010). Sensory neural codes using multiplexed temporal scales. Trends in Neurosciences, 33(3):111-20.

Paré, D. (2002). Amygdala oscillations and the consolidation of emotional memories. Trends in Cognitive Sciences, 6(7):306-314.

Pastalkova, E., Itskov, V., Amarasingham, A., and Buzsáki, G. (2008). Internally generated cell assembly sequences in the rat hippocampus. Science, 321(5894):1322-7.

Pearce, J. M., Roberts, A. D., and Good, M. (1998). Hippocampal lesions disrupt navigation based on cognitive maps but not heading vectors. Nature, 396(6706):75-77.

Pennartz, C. M. A., Lee, E., Verheul, J., Lipa, P., Barnes, C. A., and McNaughton, B. L. (2004). The Ventral Striatum in OffLine Processing: Ensemble Reactivation during Sleep and Modulation by Hippocampal Ripples. Journal of Neuroscience, 24(29):6446-6456.

Peters, J., Bromberg, U., Schneider, S., Brassen, S., Menz, M., Banaschewski, T., Conrod, P. J., Flor, H., Gallinat, J., Garavan, H., Heinz, A., Itterman, B., Lathrop, M., Martinot, J.-L., Paus, T., Poline, J.-B., Robbins, T. W., Rietschel, M., Smolka, M., Ströhle, A., Struve, M., Loth, E., Schumann, G., and Büchel, C. (2011). Lower ventral striatal activation during reward anticipation in adolescent smokers. The American Journal of Psychiatry, 168(5):540-9.

Petsche, H., Stumpf, C., and Gogolak, G. (1962). The significance of the rabbit's septum as a relay station between the midbrain and the hippocampus I. The control of hippocampus arousal activity by the septum cells. Electroencephalography and Clinical Neurophysiology, 14(2):202-211.

Poucet, B., Lenck-Santini, P. P., Hok, V., Save, E., Banquet, J. P., Gaussier, P., and Muller, R. U. (2004). Spatial navigation and hippocampal place cell firing: the problem of goal encoding. Reviews in the Neurosciences, 15(2):89-107.

Pouget, A., Deneve, S., Ducom, J. C., and Latham, P. E. (1999). Narrow versus wide tuning curves: What's best for a population code? Neural Comput, 11(1):85-90.

Ramus, S. J., Davis, J. B., Donahue, R. J., Discenza, C. B., and Waite, A. A. (2007). Interactions between the orbitofrontal cortex and the hippocampal memory system during the storage of long-term memory. Annals of the New York Academy of Sciences, 1121:216-31.

Redish, A. D. (1999). Beyond the Cognitive Map. MIT Press.

Redish, A. D. and Touretzky, D. S. (1998). The role of the hippocampus in solving the Morris water maze. Neural Computation, 10(1):73-111.

Robbe, D. and Buzsáki, G. (2009). Alteration of theta timescale dynamics of hippocampal place cells by a cannabinoid is associated with memory impairment. Journal of Neuroscience, 29(40):12597-605.

Roesch, M. R., Calu, D. J., Esber, G. R., and Schoenbaum, G. (2010). All that glitters....dissociating attention and outcomeexpectancy from prediction errors signals. Journal of Neurophysiology, 104(2):587-95. 
Rogers, J. L. and See, R. E. (2007). Selective inactivation of the ventral hippocampus attenuates cue-induced and cocaine-primed reinstatement of drug-seeking in rats. Neurobiology of Learning and Memory, 87(4):688-92.

Rosenzweig, E. S., Redish, A. D., McNaughton, B. L., and Barnes, C. A. (2003). Hippocampal map realignment and spatial learning. Nature Neuroscience, 6(6):609-15.

Royer, S., Sirota, A., Patel, J., and Buzsáki, G. (2010). Distinct representations and theta dynamics in dorsal and ventral hippocampus. Journal of Neuroscience, 30(5):1777-87.

Rutishauser, U., Ross, I. B., Mamelak, A. N., and Schuman, E. M. (2010). Human memory strength is predicted by theta-frequency phase-locking of single neurons. Nature, 464(7290):903-7.

Salamone, J. D., Correa, M., Farrar, A., and Mingote, S. M. (2007). Effort-related functions of nucleus accumbens dopamine and associated forebrain circuits. Psychopharmacology, 191(3):461-82.

Salzman, C. D. and Fusi, S. (2010). Emotion, cognition, and mental state representation in amygdala and prefrontal cortex. Annual Review of Neuroscience, 33:173-202.

Samejima, K., Ueda, Y., Doya, K., and Kimura, M. (2005). Representation of action-specific reward values in the striatum. Science, 310(5752):1337-40.

Samsonovich, A. V. and McNaughton, B. L. (1997). Path integration and cognitive mapping in a continuous attractor neural network model. Journal of Neuroscience, 17(15):5900-5920.

Scheres, A., Milham, M. P., Knutson, B., and Castellanos, F. X. (2007). Ventral striatal hyporesponsiveness during reward anticipation in attention-deficit/hyperactivity disorder. Biological Psychiatry, 61(5):720-4.

Schmidt, R., Diba, K., Leibold, C., Schmitz, D., Buzsáki, G., and Kempter, R. (2009). Single-trial phase precession in the hippocampus. Journal of Neuroscience, 29(42):13232-41.

Schultz, W., Apicella, P., Scarnati, E., and Ljungberg, T. (1992). Neuronal activity in monkey ventral striatum related to the expectation of reward. Journal of Neuroscience, 12(12):4595-4610.

Sederberg, P. B., Kahana, M. J., Howard, M. W., Donner, E. J., and Madsen, J. R. (2003). Theta and gamma oscillations during encoding predict subsequent recall. Journal of Neuroscience, 23(34):10809-10814.

Seidenbecher, T., Laxmi, T. R., Stork, O., and Pape, H.-C. (2003). Amygdalar and hippocampal theta rhythm synchronization during fear memory retrieval. Science, 301(5634):846-50.

Sejnowski, T. J. and Paulsen, O. (2006). Network oscillations: emerging computational principles. Journal of Neuroscience, 26(6):1673-6.

Sesack, S. R. and Grace, A. a. (2010). Cortico-Basal Ganglia reward network: microcircuitry. Neuropsychopharmacology, 35(1):2747.

Shapiro, M. L., Kennedy, P. J., and Ferbinteanu, J. (2006). Representing episodes in the mammalian brain. Current Opinion in Neurobiology, 16(6):701-9. 
Sharp, P. E. (2006). Subicular place cells generate the same "map" for different environments: comparison with hippocampal cells.

Behavioural Brain Research, 174(2):206-14.

Shirvalkar, P. R., Rapp, P. R., and Shapiro, M. L. (2010). Bidirectional changes to hippocampal theta-gamma comodulation predict memory for recent spatial episodes. Proceedings of the National Academy of Sciences of the United States of America, 107(15):7054-9.

Siapas, A. G., Lubenov, E. V., and Wilson, M. A. (2005). Prefrontal phase locking to hippocampal theta oscillations. Neuron, 46(1):141-51.

Sigurdsson, T., Stark, K. L., Karayiorgou, M., Gogos, J. A., and Gordon, J. a. (2010). Impaired hippocampal-prefrontal synchrony in a genetic mouse model of schizophrenia. Nature, 464(7289):763-7.

Skaggs, W. E. and McNaughton, B. L. (1996). Replay of neuronal firing sequences in rat hippocampus during sleep following spatial experience. Science, 271(5257):1870-3.

Skaggs, W. E., Mcnaughton, B. L., Wilson, M. A., and Barnes, C. A. (1996). Theta phase precession in hippocampal neuronal populations and the compression of temporal sequences. Hippocampus, 6:149-173.

Smith, D. M. and Mizumori, S. J. Y. (2006). Learning-related development of context-specific neuronal responses to places and events: the hippocampal role in context processing. Journal of Neuroscience, 26(12):3154-63.

Sutherland, R. J., Chew, G. L., Baker, J. C., and Linggard, R. C. (1987). Some limitations on the use of distal cues in place navigation by rats. Psychobiology, 15(1):48-57.

Sutton, R. S. (1990). First results with Dyna, an integrated architecture for learning, planning and reacting. Neural Networks for Control, page 179 .

Sutton, R. S. and Barto, A. G. (1998). Reinforcement learning: An introduction. MIT Press.

Swanson, L. (1981). A direct projection from Ammon's horn to prefrontal cortex in the rat. Brain Research, 217(1):150-154.

Tabuchi, E. T., Mulder, A. B., and Wiener, S. I. (2000). Position and behavioral modulation of synchronization of hippocampal and accumbens neuronal discharges in freely moving rats. Hippocampus, 10(6):717—-728.

Taverna, S., Canciani, B., and Pennartz, C. M. A. (2007). Membrane properties and synaptic connectivity of fast-spiking interneurons in rat ventral striatum. Brain Res, 1152:49-56.

Tepper, J. M., Wilson, C. J., and Koós, T. (2008). Feedforward and feedback inhibition in neostriatal GABAergic spiny neurons. Brain Research Reviews, 58(2):272-81.

Thierry, a. M., Gioanni, Y., Dégénétais, E., and Glowinski, J. (2000). Hippocampo-prefrontal cortex pathway: anatomical and electrophysiological characteristics. Hippocampus, 10(4):411-9.

Thurley, K., Leibold, C., Gundlfinger, A., Schmitz, D., and Kempter, R. (2008). Phase precession through synaptic facilitation. Neural Computation, 20(5):1285-324.

Tolman, E. C., Ritchie, B. F., and Kalish, D. (1946a). Studies in spatial learning. i. orientation and the short-cut. J Exp Psychol, 
$36: 13-24$.

Tolman, E. C., Ritchie, B. F., and Kalish, D. (1946b). Studies in spatial learning. ii. place learning versus response learning. $J$ Exp Psychol, 36:221-229.

Tremblay, L., Hollerman, J. R., and Schultz, W. (1998). Modifications of Reward Expectation-Related Neuronal Activity During Learning in Primate Striatum. J Neurophysiol, 80(2):964-977.

Tremblay, L., Worbe, Y., and Hollerman, J. R. (2009). The ventral striatum: a heterogenous structure involved in reward processing, motivation and decision-making. In Dreher, J.-C. and Tremblay, L., editors, Handbook of Reward and Decision Making, pages $51-78$.

Tsodyks, M. V., Skaggs, W. E., Sejnowski, T. J., and McNaughton, B. L. (1996). Population dynamics and theta rhythm phase precession of hippocampal place cell firing: a spiking neuron model. Hippocampus, 6(3):271-80.

van der Meer, M. A. A., Johnson, A., Schmitzer-Torbert, N. C., and Redish, A. D. (2010a). Triple Dissociation of Information Processing in Dorsal Striatum, Ventral Striatum, and Hippocampus on a Learned Spatial Decision Task. Neuron, 67(1):25-32.

van der Meer, M. A. A., Kalenscher, T., Lansink, C. S., Pennartz, C. M. A., Berke, J. D., and Redish, A. D. (2010b). Integrating early results on ventral striatal gamma oscillations in the rat. Frontiers in Neuroscience, 4(28).

van der Meer, M. A. A. and Redish, A. D. (2009). Low and High Gamma Oscillations in Rat Ventral Striatum have Distinct Relationships to Behavior, Reward, and Spiking Activity on a Learned Spatial Decision Task. Frontiers in Integrative Neuroscience, $3: 9$.

van der Meer, M. A. A. and Redish, A. D. (2010). Expectancies in Decision Making, Reinforcement Learning, and Ventral Striatum. Frontiers in Neuroscience.

van der Meer, M. A. A. and Redish, A. D. (2011a). Theta Phase Precession in Rat Ventral Striatum Links Place and Reward Information. Journal of Neuroscience, 31(8):2843-2854.

van der Meer, M. A. A. and Redish, A. D. (2011b). Ventral striatum: a critical look at models of learning and evaluation. Current Opinion in Neurobiology, 21(3):387-92.

van Wingerden, M., Vinck, M., Lankelma, J., and Pennartz, C. M. A. (2010). Theta-band phase locking of orbitofrontal neurons during reward expectancy. Journal of Neuroscience, 30(20):7078-87.

Vanderwolf, C. (1969). Hippocampal electrical activity and voluntary movement in the rat. Electroencephalography and Clinical Neurophysiology, 26(4):407-418.

Voorn, P., Vanderschuren, L. J., Groenewegen, H. J., Robbins, T. W., and Pennartz, C. M. (2004). Putting a spin on the dorsal-ventral divide of the striatum. Trends in Neuroscience, 27:468-474.

Vorel, S. R., Liu, X., Hayes, R. J., Spector, J. a., and Gardner, E. L. (2001). Relapse to cocaine-seeking after hippocampal theta burst stimulation. Science, 292(5519):1175-8.

Wallenstein, G. V. and Hasselmo, M. E. (1997). GABAergic modulation of hippocampal population activity: sequence learning, 
place field development, and the phase precession effect. Journal of Neurophysiology, 78(1):393-408.

Wang, X.-J. (2010). Neurophysiological and computational principles of cortical rhythms in cognition. Physiological reviews, 90(3):1195-268.

Whishaw, I. Q., Hines, D. J., and Wallace, D. G. (2001). Dead reckoning (path integration) requires the hippocampal formation: evidence from spontaneous exploration and spatial learning tasks in light (allothetic) and dark (idiothetic) tests. Behavioural Brain Research, 127:49-69.

Whishaw, I. Q. and Mittleman, G. (1991). Hippocampal modulation of nucleus accumbens: behavioral evidence from amphetamineinduced activity profiles. Behavioral and Neural Biology, 55(3):289-306.

Wise, R. A. (2006). Role of brain dopamine in food reward and reinforcement. Philos. Trans. R. Soc. Lond. B Biol. Sci., 361:11491158 .

Womelsdorf, T., Vinck, M., Leung, L. S., and Everling, S. (2010). Selective theta-synchronization of choice-relevant information subserves goal-directed behavior. Frontiers in Human Neuroscience, 4:210.

Yamaguchi, Y. (2003). A theory of hippocampal memory based on theta phase precession. Biological cybernetics, 89(1):1-9.

Yamaguchi, Y., Sato, N., Wagatsuma, H., Wu, Z., Molter, C., and Aota, Y. (2007). A unified view of theta-phase coding in the entorhinal-hippocampal system. Current Opinion in Neurobiology, 17(2):197-204.

Ylinen, A., Soltész, I., Bragin, A., Penttonen, M., Sik, A., and Buzsáki, G. (1995). Intracellular correlates of hippocampal theta rhythm in identified pyramidal cells, granule cells, and basket cells. Hippocampus, 5(1):78-90.

Zhang, K. and Sejnowski, T. J. (1999). Neuronal tuning: To sharpen or broaden? Neural Computation, 11(1):75-84.

Zilli, E. A. and Hasselmo, M. E. (2008). Modeling the role of working memory and episodic memory in behavioral tasks. Hippocampus. 
A
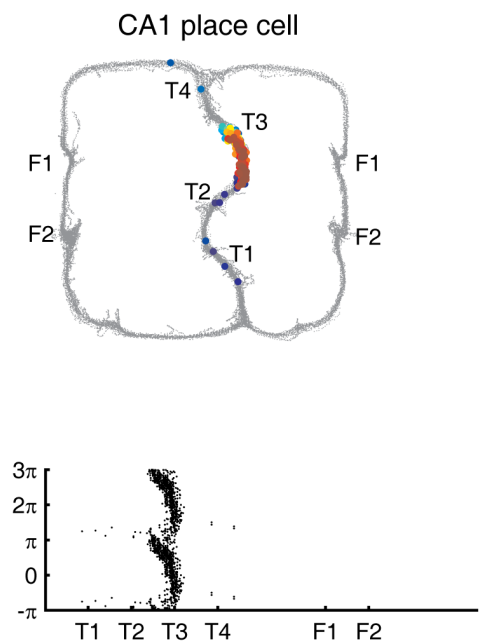

C

ventral striatal "ramp" cell
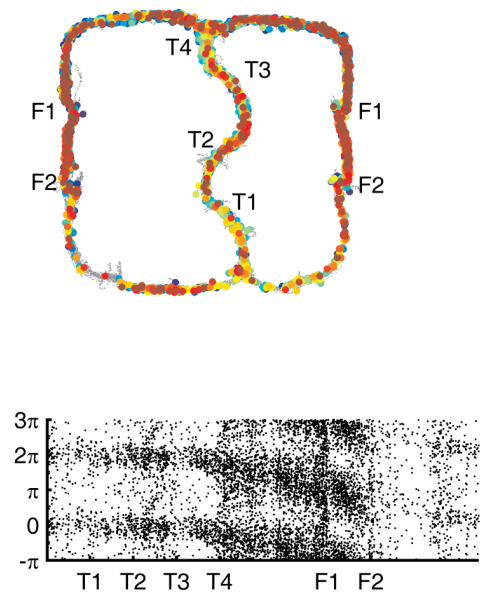

B

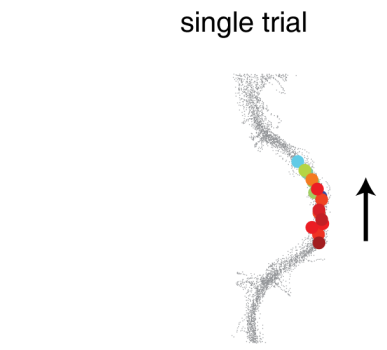

mpryform

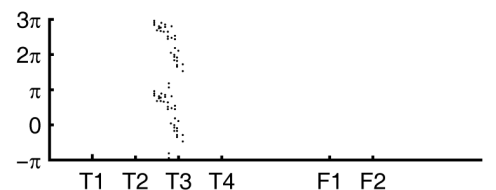

D
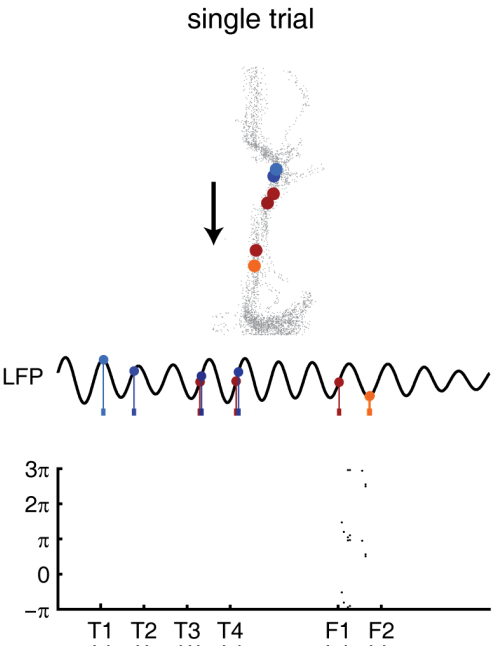

Figure 1: Examples of theta phase precession in a dorsal CA1 "place" cell (A-B, a putative pyramidal neuron) and a ventral striatal "ramp" cell (C-D, a putative medium spiny neuron), recorded simultaneously from a rat running on an elevated track. The left column shows the spikes of each neuron by position of the animal on the track, color coded by theta phase (top); phase is also shown along a linearized, one-dimensional view of the track (bottom). T1-T4 indicate turns on the track, F1 and F2 are reward sites. The right column shows a single pass through each neuron's firing field, with spikes shown alongside the theta-filtered local field potential (recorded from the hippocampal fissure in both cases), color coded on the same scale. The arrow indicates the animal's direction of travel. Phase precession is apparent both in the combined and single-trial plots, but note how phase precesses more rapidly in the hippocampal neuron. Data from van der Meer and Redish (2011a). 
A

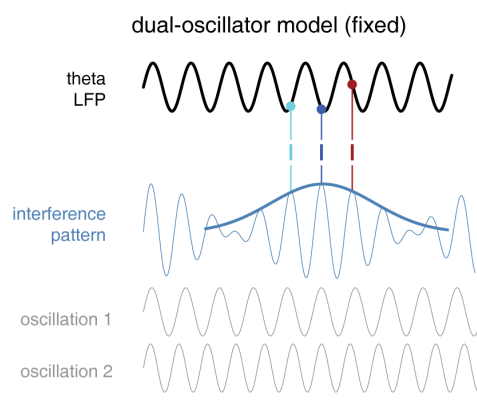

B

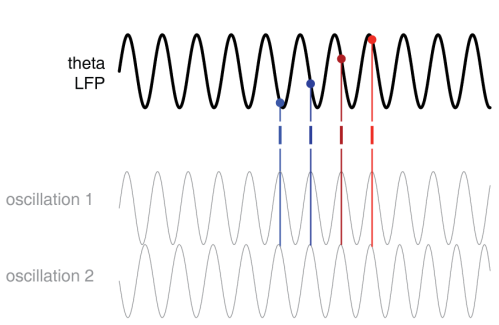

C

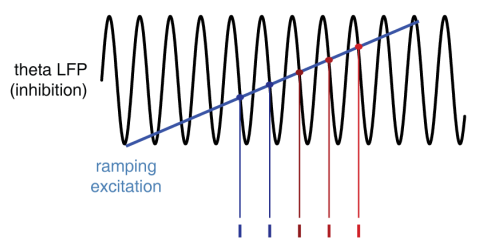

D
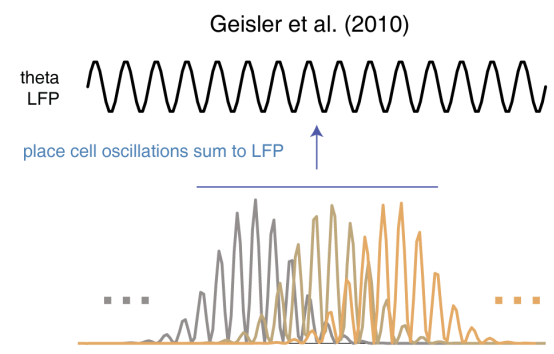

E

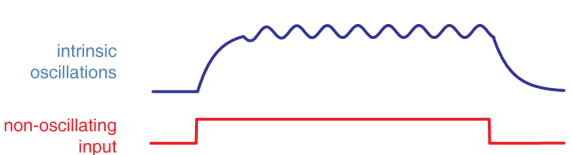

resonance

frequency

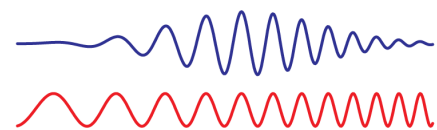

$\mathrm{F}$

passive membrane properties

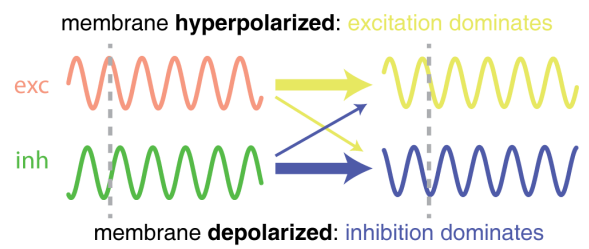

Figure 2: Possible contributions to the generation of theta phase precession. In the classical dualoscillator model (A; O'Keefe and Recce 1993) a phase precessing cell receives two oscillating input signals with fixed, but slightly different, frequencies; the slower one of these corresponds to the LFP frequency. When summed, these oscillations generate an interference or "beat" pattern. Within a beat (indicated by the gaussian firing profile of a putative place cell) the frequency of the interference pattern is faster than that of the LFP, as indicated by the phase precessing spikes (color indicates phase). A variation of this model (B) occurs when one of the oscillations is frequencymodulated; in this case, two oscillations can be out of phase outside the neuron's place field, but in phase in the place field. As long as both oscillations are faster than the LFP, the resulting spikes will phase precess (Lengyel et al., 2003; Yamaguchi et al., 2007). C: Asymmetric ramping excitation interacting with rhythmic inhibition at LFP frequency (Mehta et al., 2002). As excitation increases, the LFP phase of the point at which excitation exceeds inhibition precesses. D: A different view, focusing on the relationship between membrane potential oscillations in place cells (bottom) and the resulting LFP (top). With appropriate offsets between cells, the LFP frequency can be lower than that in any single place cell (Geisler et al., 2010). E: Active membrane properties can convert a non-oscillating input into an oscillation (top) or filter oscillating input through resonance (bottom). F: The effectiveness of phase-shifted inhibitory and excitatory inputs respectively depends on the membrane potential, leading to a phase shift as the membrane depolarizes (Leung, 2011). 


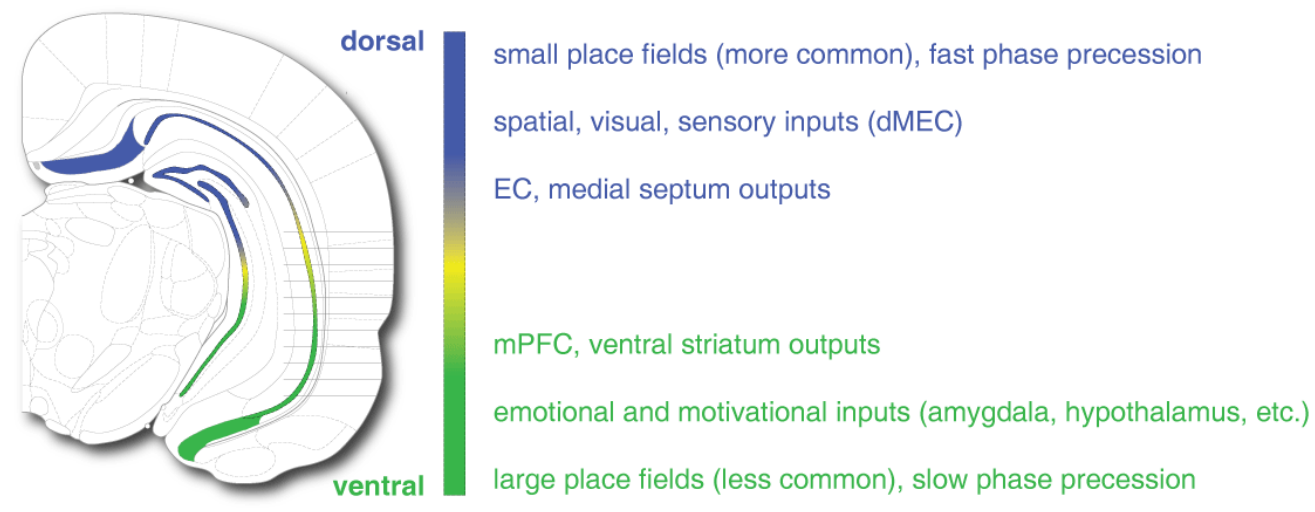

Figure 3: Different aspects of the hippocampus map onto distinct anatomical and functional subsystems. Theta phase precession follows a gradient from dorsal to ventral in the hippocampus proper, with the proportion and strength of phase precessing cells decreasing towards the ventral aspect (Royer et al., 2010). This organization mirrors the gradual increase in place field size, and degradation of the place representation towards the ventral aspect (Jung et al., 1994; Kjelstrup et al., 2008). (It is worth pointing out that the larger size of individual place cells, by itself, need not imply a less "spatial" code - at the population level, the optimal tuning width depends on factors such as the correlational structure and the time window available for decoding (Zhang and Sejnowski, 1999; Pouget et al., 1999; Berens et al., 2011); however, apart from the larger field size in the ventral hippocampus, there seem to be less neurons with place (and theta) modulation, supporting the notion that the code for place degrades along the dorsal-ventral axis.) In turn, hippocampal dorsal-ventral organization is thought to derive from a comparable gradient from dorsal to ventral medial entorhinal cortex, along which grid cells increase their spacing (Giocomo et al., 2007; Yamaguchi et al., 2007; Blair et al., 2008; de Almeida et al., 2009) as well as from different mixing of medial entorhinal and lateral entorhinal inputs (Amaral and Lavenex, 2006). Corresponding dissociations exist in the functional role of the dorsal, intermediate, and ventral aspects (see e.g. Bast 2007; Fanselow and Dong 2010 for review). Less is known about the subiculum, which receives inputs from CA1 and is a major source of projections to medial prefrontal cortex (mPFC) and the ventral striatum (vStr). The extant recording data indicate that the dorsal subiculum displays less context dependence than dorsal CA1/CA3 (Sharp, 2006), but to our knowledge the coding properties of ventral subicular neurons are not known. Figure adapted from Paxinos and Watson (2007). 


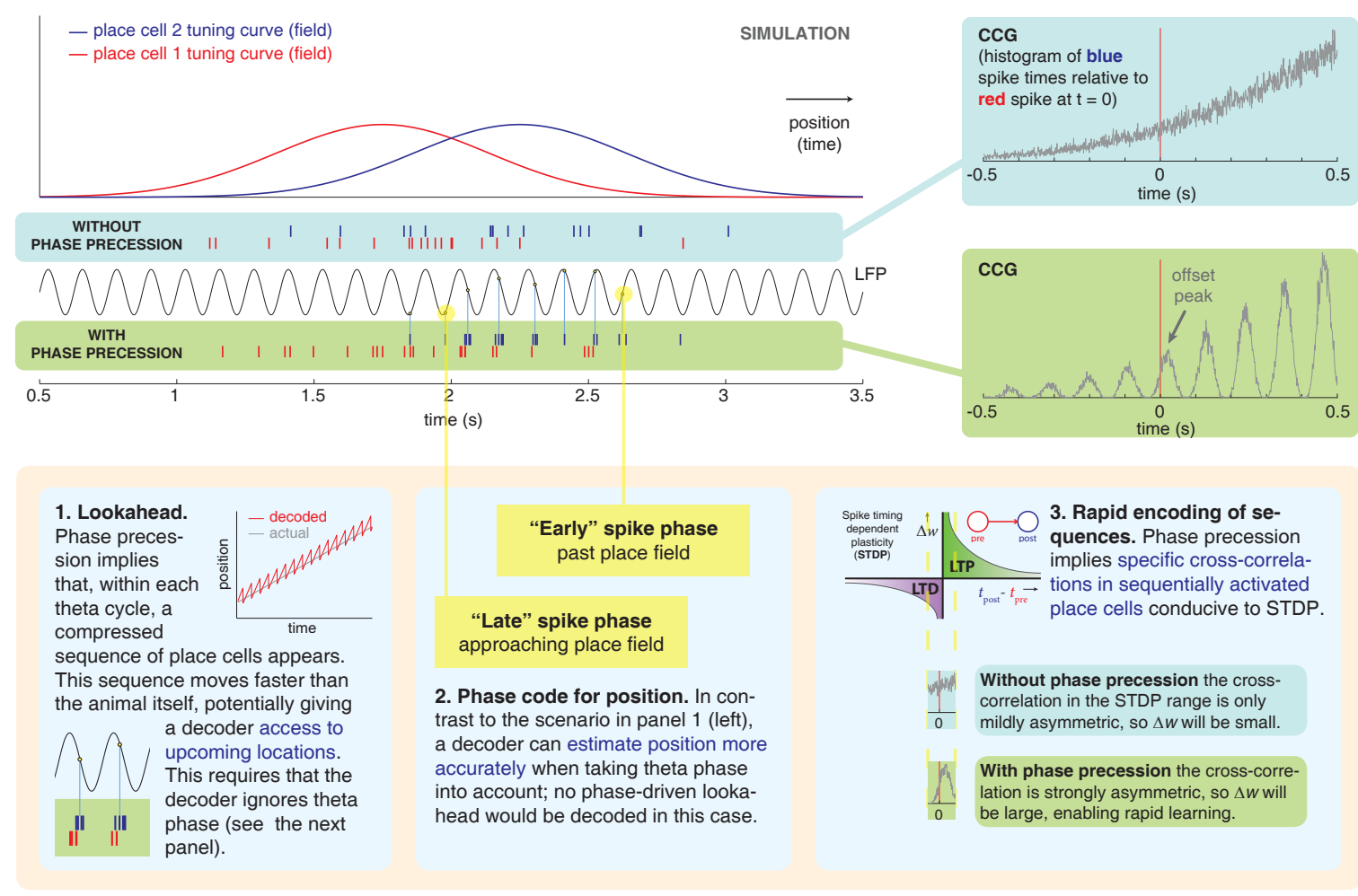

Figure 4: Schematic illustration of possible functional roles of phase precession in the hippocampus: (1) lookahead, (2) phase coding, and (3) rapid learning. The top left panel shows a simulation of a single run through two adjacent, idealized place cells (from left to right; "red" place cell followed by "blue" place cell). In the hypothetical case of no theta phase precession, the pattern of spikes during the run would look like that in the blue panel ("without phase precession"). On average, the blue spikes appear later than the red spikes, reflecting the order of the place fields. However, little structure is apparent at a finer timescale: that is, sometimes a blue spike comes before, sometimes after a red spike. This is illustrated by the cross-correlogram (top right "CCG" panel; computed across many runs) which shows a slow asymmetry of blue spikes relative to red spikes (aligned to $t=0$ ). This scenario contrasts with phase precession (green panel, "with phase precession") where a systematic, fine-timescale pattern emerges: the blue spikes tend to come just after the red spikes within each theta cycle. As a result, the cross-correlogram exhibits a peak in the $\sim 20 \mathrm{~ms}$ range, conducive to spike-timing dependent synaptic potentiation (green CCG panel). Thus, within a theta cycle, theta sequences form, consisting of a coherent sequence or path of place cells which enables the animal to represent upcoming locations ("lookahead"; lower left panel, Jensen and Lisman 1996). The phase of each spike contains information about location, a phase code for position (lower center panel, Jensen and Lisman 2000). Finally, the ordering of spikes within a theta cycle places them in the range of spike-timing dependent plasticity (STDP; lower right panel, Skaggs et al. 1996). 


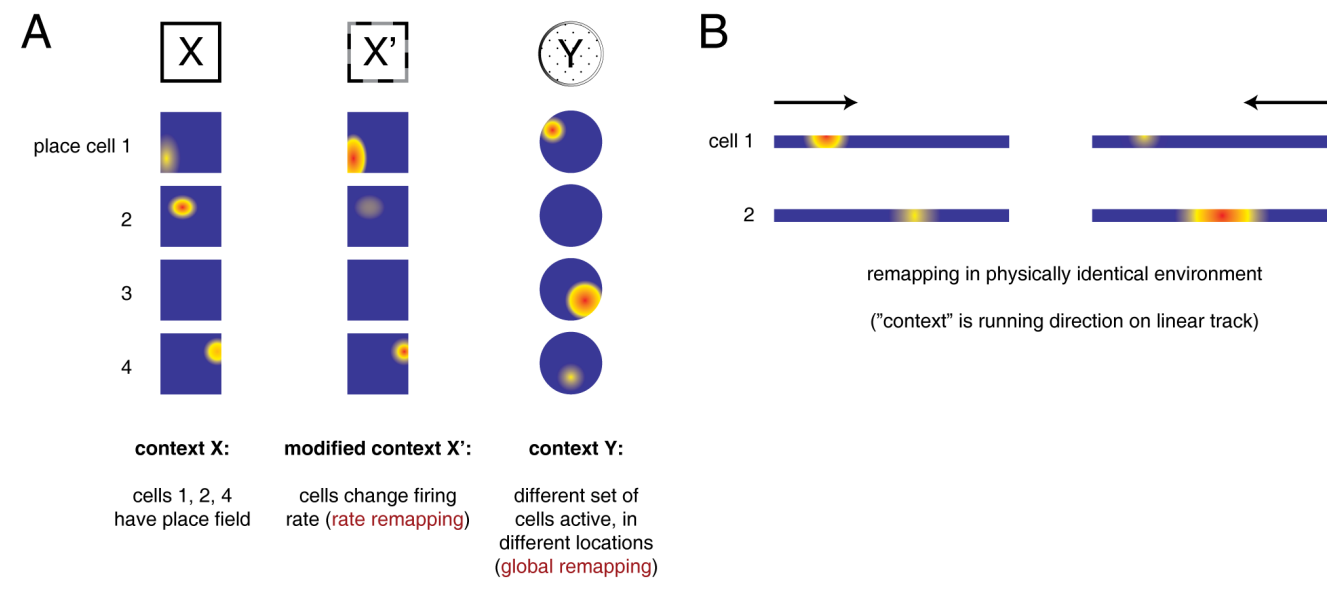

Figure 5: Representations of place and context in the hippocampus. A: The hippocampal code for place recruits a specific set of neurons for a given context or environment, such as a square box (context X). Each neuron that participates in the "map" for this context has a spatially tuned receptive field ("place field", red indicates elevated firing rate, blue indicates zero), such that together, these place cells represent the organism's location within this context. (For instance, if place cells 1 and 2 were simultaneously active, this would indicate the animal is likely to be at the location where the two cells' fields overlap.) When the organism is returned to this environment at some later time, the same set of place cells will be active at the same locations in the environment: the hippocampus recalls the same "map". Minor changes in the environment (context X') can result in changes firing rate ("rate remapping", Leutgeb et al. 2005b). Major changes in the environment (context $Y$ ) results in a different set of place cells being active ("global remapping"). Thus, the hippocampus represents context, as well as the animal's place within it, using the same population of neurons. In decoding which context an animal is in based on hippocampal firing patterns alone, no single place cell provides sufficient information. Rather, the combination of which place cells are active together for a given location distinguishes the context (Jeffery et al., 2004). B: Remapping can also occur without changes in the environment, but as a function of the animal's internal segmentation of it. Here, left and right runs on a linear track result in remapping (McNaughton et al., 1983). 
A

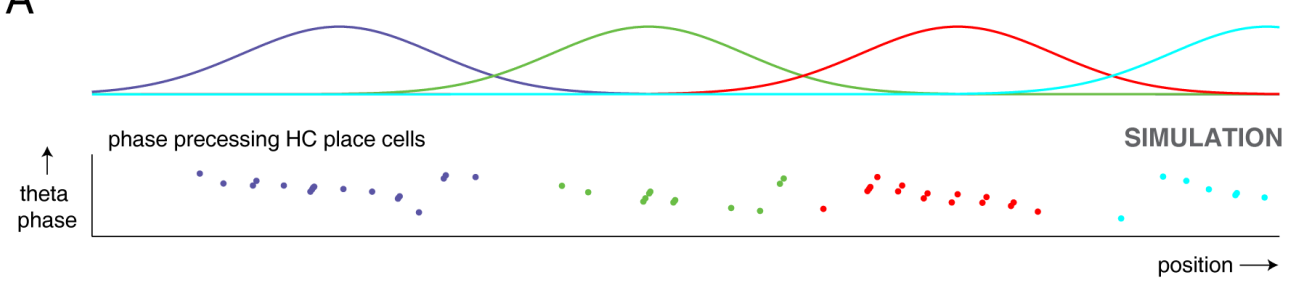

B before learning: randomly connected $\mathrm{HC}$-vStr projection
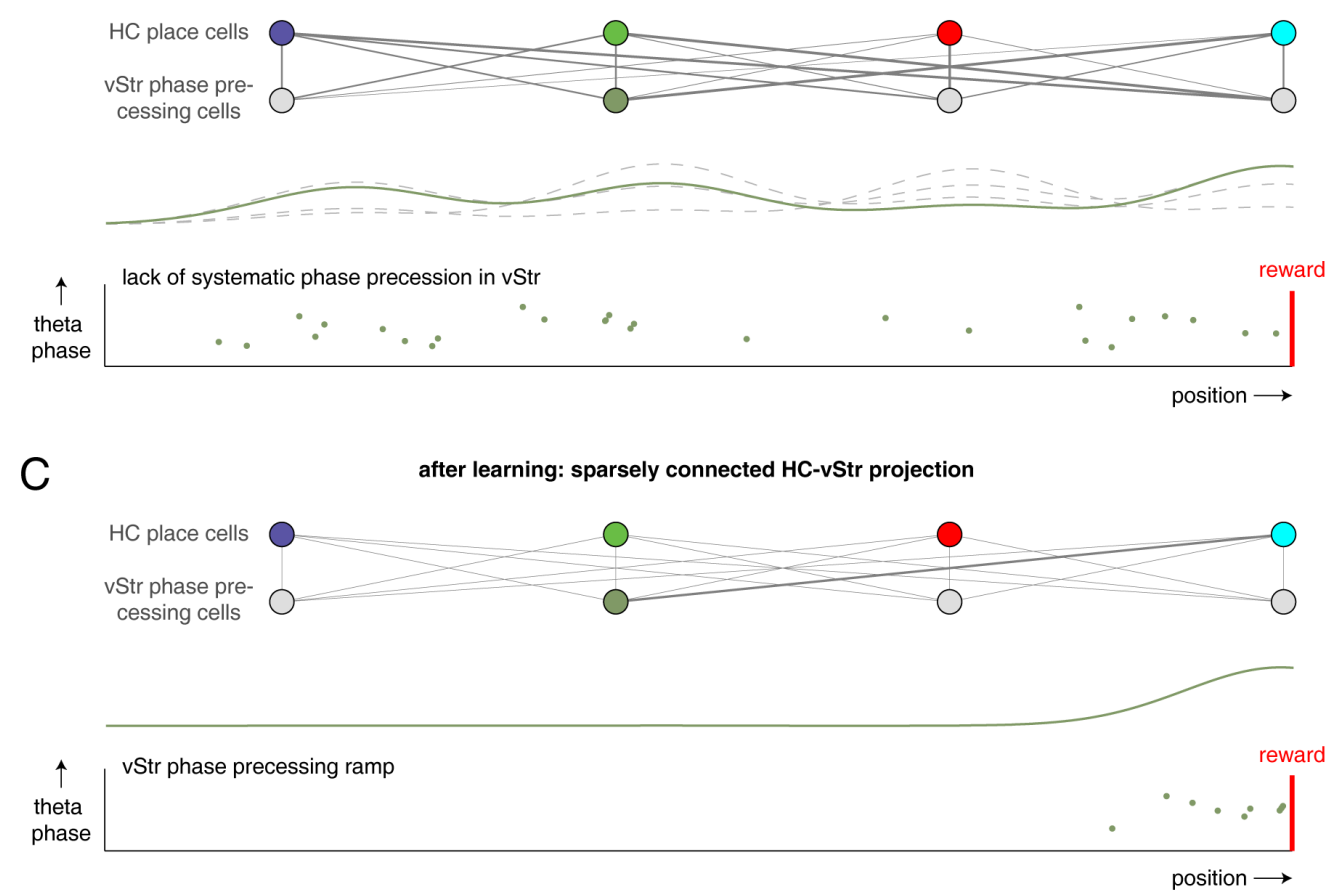

Figure 6: Schematic of hypothesized hippocampus (HC)-ventral striatum (vStr) interactions during learning, illustrating how ventral striatal phase precession can reveal the pattern of hippocampal inputs to a ventral striatal neuron. A: Spatial tuning curves ("place fields") of four hippocampal place cells arranged on a linear track, along with a sample phase precession pattern as the animal runs along the track from left to right. B: Model network with randomly weighted, all-to-all connectivity between the four place cells in A (top row) and putative ventral striatal cells (bottom row). Random connectivity results in diffuse ventral striatal activity along the track; highlighted is the tuning curve of a single vStr neuron (dark green line and spike phase plot). Because this neuron's activity is driven by a combination of different phase precessing place cells, its spatial tuning curve is relatively nonspecific, and its pattern of phase precession erratic. This scenario may correspond to a naive animal first introduced to an environment. C: As the animal learns about reward locations, a three-factor learning rule that depends on hippocampal, ventral striatal, and dopamine activity may strengthen specific HC-vStr synapses. As a result, after learning, the vStr neuron's firing and phase precession pattern over the track changes from spatially diffuse to systematic ramping: it selectively inherits a particular phase precession pattern. 
unrewarded theta sequence
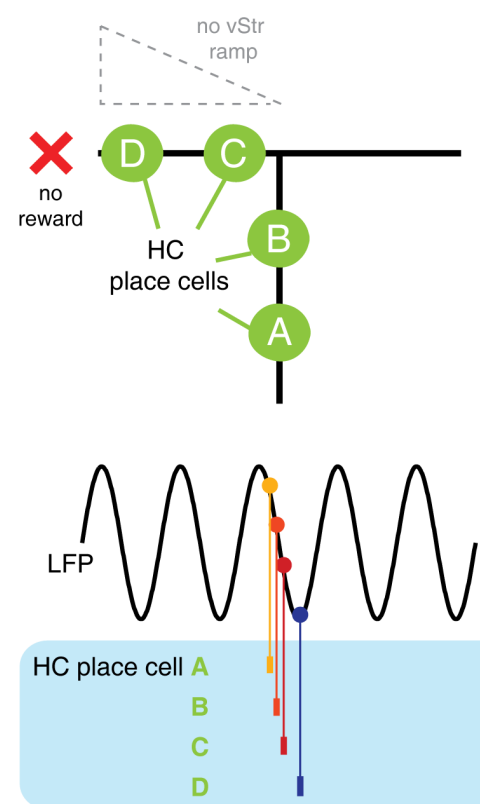

rewarded theta sequence
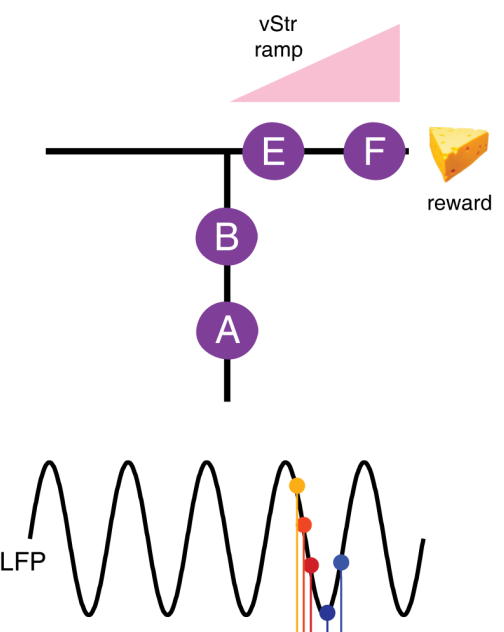

HC place cell A

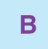

E

$\mathbf{F}$

I

Figure 7: Schematic of hypothesized hippocampus-ventral striatum interaction during behavior (theta sequences). As the animal faces a left/right choice at a T-maze, subsequent theta sequences traverse different parts of the maze, first to the unrewarded left side (left panel) and then to the rewarded right side (right panel). Shown schematically are the place field centers of hippocampal place cells (labeled A-F, top panels). In other words, the animal is paused - but attentive - at location $A$, such that a theta sequence extends first to the unrewarded side of the maze (place cells ABCD). This sequence is ineffective in triggering ventral striatal ramp cell activity (no 'vStr' spike in the bottom panel). On the next theta cycle, a different theta sequence (place cells ABEF) occurs, to the rewarded side of the maze. Based on previous association with a ventral striatal ramp cell (pink ramp), this sequence triggers a ramp cell spike ('vStr' spike at the late theta phase in the bottom panel). The conjunction of activity in the choice-specific place cells EF and the ventral striatal neuron at a late phase of theta constitutes a potentially informative cue for biasing behavioral choice (van der Meer and Redish, 2010). 


\begin{tabular}{|c|c|}
\hline 1. & $\begin{array}{l}\text { Generality of extrahippocampal theta phase precession } \\
\text { Does theta phase precession occur in other structures known to } \\
\text { be theta-modulated and anatomically related to the hippocampus } \\
\text { and/or the ventral striatum, such as the amygdala, orbitofrontal } \\
\text { cortex, and dorsal raphe? } \\
\text { Does ventral striatal phase precession occur on non-spatial tasks, } \\
\text { such as during a delayed-reward waiting period (e.g. Khamassi } \\
\text { et al. 2008)? }\end{array}$ \\
\hline 4. & $\begin{array}{l}\text { Source of ventral striatal phase precession } \\
\text { Does the development and maintenance of ventral striatal phase } \\
\text { precession depend on hippocampal input? } \\
\text { Are ventral striatal phase precessing cells "copies" of ventral hip- } \\
\text { pocampal cells with similar firing patterns (Royer et al., 2010)? }\end{array}$ \\
\hline 6. & $\begin{array}{l}\text { Role of the subiculum } \\
\text { Do (ventral) subicular cells phase precess and form theta se- } \\
\text { quences? } \\
\text { How does the ventral subiculum represent places, contexts, and } \\
\text { rewards? }\end{array}$ \\
\hline 8. & $\begin{array}{l}\text { Properties of ventral striatal phase precessing cells } \\
\text { Do ventral striatal phase precessing cells participate in theta se- } \\
\text { quences, within ventral striatum and with hippocampal place } \\
\text { cells? } \\
\text { Do ventral striatal phase precessing cells carry independent rate } \\
\text { and phase codes, such as for distance to and magnitude of ex- } \\
\text { pected reward? }\end{array}$ \\
\hline 10. & $\begin{array}{l}\text { Ventral striatal phase precession and decision making } \\
\text { To what extent do phase precessing cells reflect past vs. current } \\
\text { reward values? } \\
\text { What is the impact of ventral striatal firing phase on interneurons } \\
\text { and downstream targets? }\end{array}$ \\
\hline 12. & $\begin{array}{l}\text { Learning of place-reward associations } \\
\text { How does ventral striatal phase precession develop? Are ventral } \\
\text { striatal phase precessing cells theta-modulated or phase precess- } \\
\text { ing when an animal is first exposed to a novel environment? } \\
\text { How do ventral striatal phase precessing cells, as a population, re- } \\
\text { spond to hippocampal remapping and context changes more gen- } \\
\text { erally? }\end{array}$ \\
\hline
\end{tabular}

Table 1: Some open questions about extrahippocampal phase precession. 